\title{
EFFECT OF DIFFERENT TYPES OF WASTE MATERIALS USED BETWEEN DOUBLE GLAZING BOX TO ISOLATE FATIGUE TEST MACHINE NOISE
}

\author{
Samheri A. Almuradi*
}

Mech. Eng. Dept., Faculty of Engineering, Al-Mustansiriyah University, Baghdad, Iraq, P.O. Box (46049)

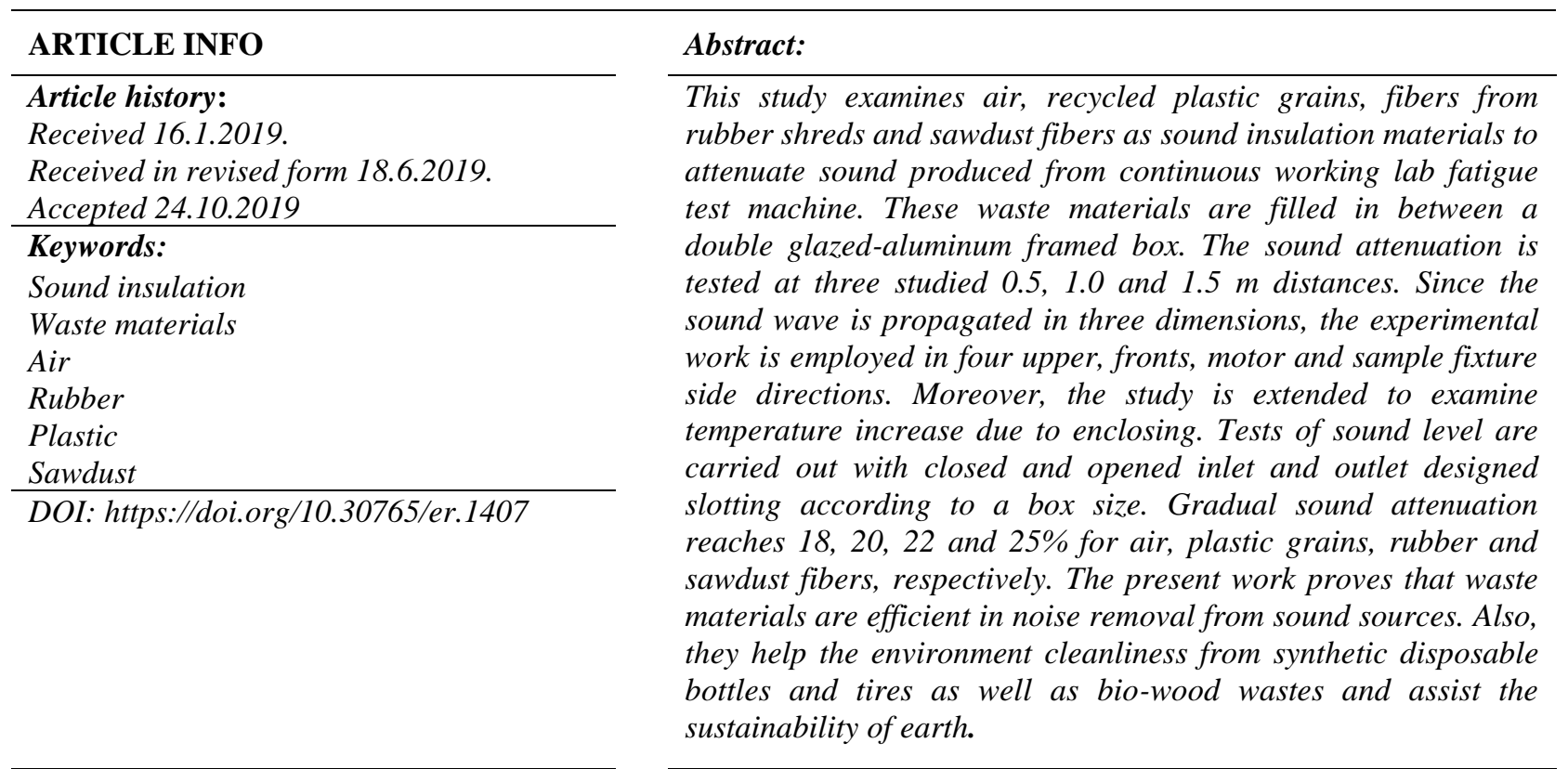

\section{Introduction}

The annoyance effects are not recognized exactly. It is flexible and depends on the receiver. Some make it acceptable, other make it unacceptable. The main causes of the noise are:

(1) Transportation means;

(2) Construction processes;

(3) Electrical devices.;

(4) Industry machines;

(5) Public busy places with its instruments, Australian National code [1].

Noise types are classified into:

(1) Ambient (Continuous);

(2) Impulse (Sudden);

(3) Transient (Continuous and variable);

(4) Environmental (Comprehensive for all the above outside and inside buildings), Suter [2].

\subsection{Negative Noise Effect}

They concentrated on two types of general human health:

(1) Hearing damage partially or permanently,

(2) Human body system defect, Berglund and Lindvall [3] \& Caniato et al. [4].

\footnotetext{
* Corresponding author

E-mail address: samheri@uomustansiriyah.edu.iq
} 


\subsection{Noise and Annoyance}

Annoyance differs depending on sound receiver and sound source. Generally, most receivers annoy starts with $55 \mathrm{~dB}$ sources. Studies showed that about $30 \%$ of them are annoyed from a plane noise, $20 \%$ from a vehicle noise and $10 \%$ from a train's noise. Some of them feel annoyed at $40 \mathrm{~dB}$ sources, Schultz [5], Jakobsen [6] \& Drexl et al. [7].

\subsection{Accepted Noise Level}

From the most prominent recommendations from the World Health Organization about the sustainable environment inside buildings at 2,000 are:

(1) Noise source must not be higher than $30 \mathrm{~dB}$ during night.

(2) It should not be higher than 50-55 dB during day, WHO [8].

\subsection{Sound Sources}

They are divided into three types, Smith et al. [9], :

(1) Point source; the sound waves spread spherically whenever far away from a source, like machines in general.

(2) Line source; it is a long line sound source on a single coordinate. It can be represented as a series of point sources. The sound spreads away in cylindrical shape far from a source like a series of machines.

(3) Plane source; it is a series of point sources distributes in two directions but within the same plane. The sound waves spread as a rectangular plane parallel to the sound source plane like multi-line machines.

\subsection{Machine Sound Attenuation}

Most of the effective machine sound insulation methods are:

(1) Using silencers especially for internal combustion engines application.

(2) Acoustical enclosure with electrical and electronic machines.

(3) Screen to separate the space which has sound source from other spaces with a wall or walls.

One of the main causes for noise inside buildings is a machine. Inside the labs there are many machines worked at different noise levels. The period of existence of such noise is so important. In Mechanical labs some machines have high noise level but with short periods of work. One of the noisy and long term period of work until the specimen failure is fatigue test machine. Its sound is attenuated using the most applicable acoustical enclosure method for lab space. It is a structure that has a specified dimension bounding the sound source in order to attenuate about $20-45 \mathrm{~dB}$ of sound levels depending on the walls structure material, Templeton [10]. EPD [11] found that aluminum metal was better as sound insulation than steel for same weight condition. Virgan [12] showed two types of sound insulation improvements in glass materials. First sound insulation efficiency increased as glass thickness increased. Second insulation effect increased with an increased number of glass layer with an allowed condition of a specified distance for air cavity.

DAAF [13] confirmed the information of previous reference and allocated them for low frequency sound source applications. Smith et al. [9] showed the range of a hearing sound level in human ear for 20-100 Hz frequency to be maximum between 30-130 dB. The acceptable sound level, particularly in labs, is to be not higher than $29 \mathrm{~dB}$, and $34 \mathrm{~dB}$ for sound comfort, Miedema and Oudshoorn [14]. The calculation of a frequency level for the fatigue test machine depending on motor revolutions per minute and velocity transmission is within $100 \mathrm{~Hz}$ (low frequency source), Perrson et al. [15] \& Vercammen [16 \&17]. Bradley [18] examined different sound insulation materials at different frequency range. He found that porous materials having air cavities were the appropriate for low frequency sound sources $(50-200 \mathrm{~Hz})$. Kuttrruff [19] explained that type of material used in sound insulation for all the mentioned methods played the main rule.

The insulation material is of one or multi-mixed built or non-built used to attenuate sound waves. It must have the following specifications to be applicable: 
(1) Cheap, (2) Lightweight, (3) Have higher absorption efficiency, (4) Low environment pollution, (5) Anti $\mathrm{CO}_{2}$ production, Asdrubali [20] and Asdrubali et al. [21] \& Kyaw et al. [22], (6) Not a carcinogen material, Arenas \& Chrocker [23].

The earth environment prevention takes the priority in the scientific efforts of countries, communities and research centers nowadays. Related studies show that synthetic waste of plastic (bottles) and rubber (tires) as well as bio-waste of sawdust (trees) has mainly contributed to environmental pollution. Generally, most of the latest works are concentrated on using waste materials for thermal and acoustical insulation, Sukontasukkul [24], ECF [25] and Asdrubali et al. [26]. Koizumi et al. [27] showed that sound absorption efficiency increased as insulation material grain or fiber amount increased (using smaller sizes of grain or fiber), which in turn increased the surface area of friction and led to higher loss of sound energy. Yang \& Li [28] proved separately that the increase in air connected cavities bounded such grains and fibers will increase the sound attenuation phenomena. Sagartzazu et al. [29] pointed out the reason of the sound attenuation for waste materials due to three processes:

(1) During incidence of sound waves a viscous effect takes place between grains or fibers and bounded air leading to attenuate part of sound energy converts it into heat energy.

(2) The difference between grains or fibers temperature due to friction will create an isothermal heat transfer and help in sound energy dissipation.

(3) The air molecule's vibration will be transmitted into grain or fiber materials. This air vibration within lumens between grains and fibers increases the absorption of sound energy compared to solid structures, Allard et al. [30] \& Voronina [31].

Li et al. [32] \& Bahrambeygi et al. [33] showed that more complex grains or fibers contain smaller subfibers and each sub-fiber contains millions of nanofibers. This structure helps a lot in fragmentation of sound waves and improved sound energy absorption by increasing friction surface area. Yang \& Li [28] explained separately that fine smaller sub-fibers with its nanofibers increase the quantity of vibrations leading to higher energy loss of sound.

The aim of the present study is to attenuate the sound produced from a fatigue test machine inside the lab by using double glass aluminum framed box as an acoustical enclosure. Many waste materials (plastic grains, shredded rubber fibers and sawdust fibers, in addition to air) are sandwiched between the glass sheets. The study is one of the means to get rid of the huge amounts of synthetic waste that comes from plastic bottles and rubber tires, as well as bio-waste that comes from wood of trees as one of the solutions to clean environment. The work finds an optimum sound insulation, cheap and more efficient in low frequency sound sources.

\section{Experimental Work}

The experimentation starts with design and manufacture of a structure that encloses the machine of a small size as to do the heat transfer required as well as sound absorption. WAS THIS THE MEANING? The structure includes rigid frame fixes, the double glazing walls sandwiched by air and waste material fibers and grains.

The experimental apparatus parts are:

(1) Fatigue test machine,

(2) Double glazing Aluminum frame box,

(3) Instruments of measurement.

\subsection{Fatigue Test Machine}

It represents the sound source inside the lab. It consists of many parts. Every part can be assumed as a sound source by itself. It manufactured by Hi-Tech Company for lab apparatus, as shown in Figure (1). 

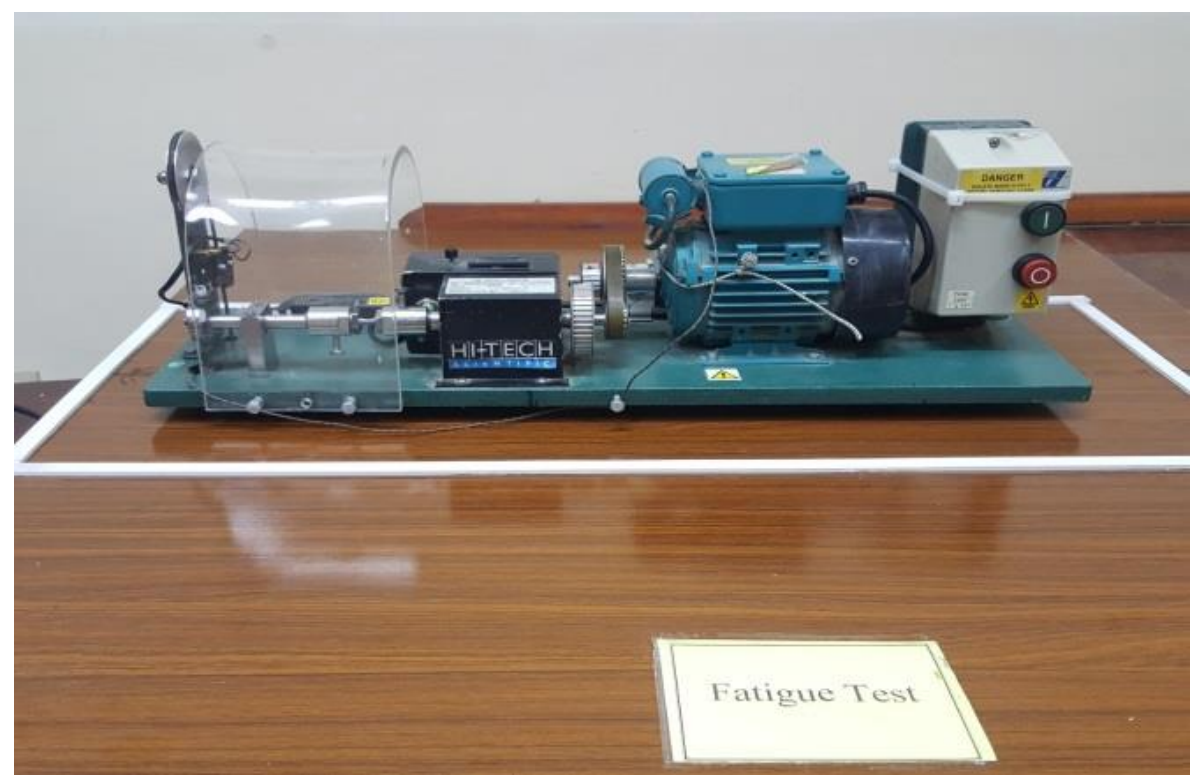

Figure 1. Fatigue test machine.

The first part is an electrical motor as a main prime mover for the machine. The motor is cooled by compact air fan. It is $1.24 \mathrm{~A}, 220 \mathrm{~V}$ and $2870 \mathrm{rpm}$, of type PDA63SG IP55 IC411 Brook Invensys Crompton. The second part is motion transmission system. It works by means of a conveyor belt to get equal, half or doubled of motor speed depending on transmission wheel size. The transmission output shaft holds the fixed side of the sample test fixture. The third part is a classical fatigue test sample. It is made of a mild steel to expand the period of failure. The fourth part is a free side sample fixture. It is connected to loads (weights) by a rope passed through a hole in a thickened wood basement of the machine. The exact sound source of every part of the machine is coming from its frictional parts of the bearings. These bearings are distributed into two bearings hold motor rotor, another two bearings hold transmission rotor and the last bearing holds the free side of a sample fixture.

\subsection{Double Glazing Aluminum Frame Box}

It is a downward open box of 40X40X90 cm in dimensions. These dimensions are carefully designed to allow enough space surrounding the machine for forced air convection cooling. The box frame is made of aluminum. Every side is made of a double $6 \mathrm{~mm}$ thickness of natural transparent window glass, as shown in Figure (2).

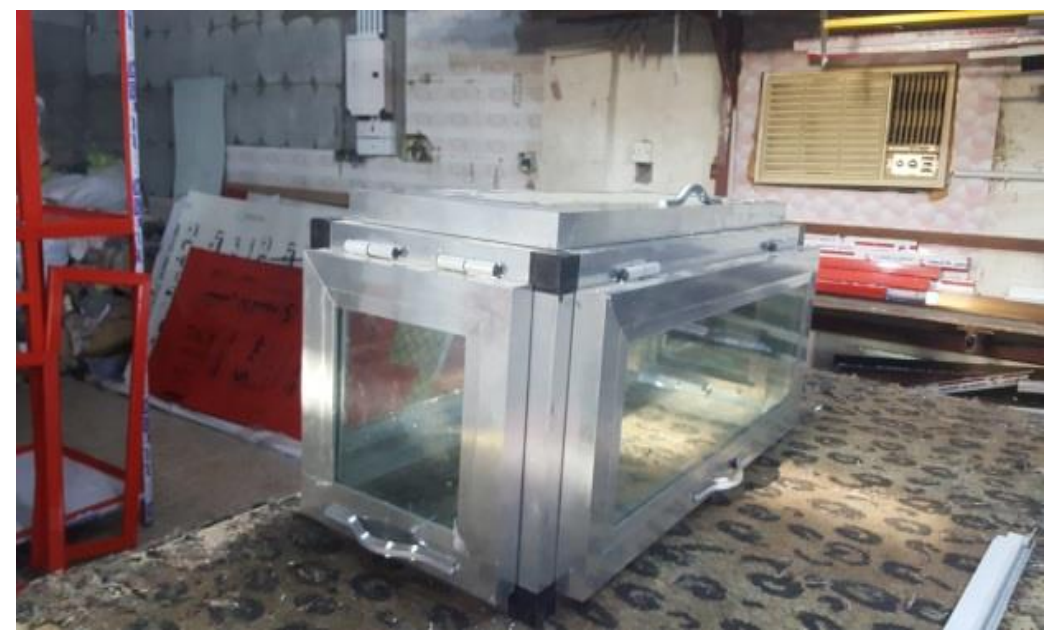

Figure 2. Isometric view of the double glazing aluminum frame box during manufacturing. 
Air gap of $8 \mathrm{~mm}$ separates between the glass sheets. The glass is fixed securely inside the frame by bolts and using silicon paste to get perfect isolation. The structure can be disassembled easily. To insure the machine cooling within the box, two slots $(200 \times 2 \mathrm{~mm})$ are made in the box frame, one at the lower part of motor side (air inlet) and the second at the upper part of sample fixture side (air exit).

\subsection{Preparation of Insulation Material}

Plastic wastes are cut into small grains using fine hole's kitchen grater tool. Rubber wastes are shredded and cut into small fibers using meat grinder machine. The wood wastes are cut into small parts using saws and cut into small fibers using block plane. For experimentation requirement only the shredding and cutting processes were used with no heat treatment process. The fibers and grains are added and arranged as in attachment, without adhesion to allow air penetration (porous attenuation process).

\subsubsection{Material Addition}

The addition process of insulation material to box requires:

- Disassembling of each side double glazing fixtures, as shown in Figure (3).

- Raising one sheet of double glazing assembly.

- Adding material of one type each time between the other sheet and bounded separator for all sides, as shown in Figure (4).

- Leveling of material grains or fibers.

- Mounting the raised sheet and fixing it upon the separator with silicon paste, as shown in Figure (5) $\&(6)$.

- Assembling glass groups inside the box frame, as shown in Figure (11), (12) and (13).

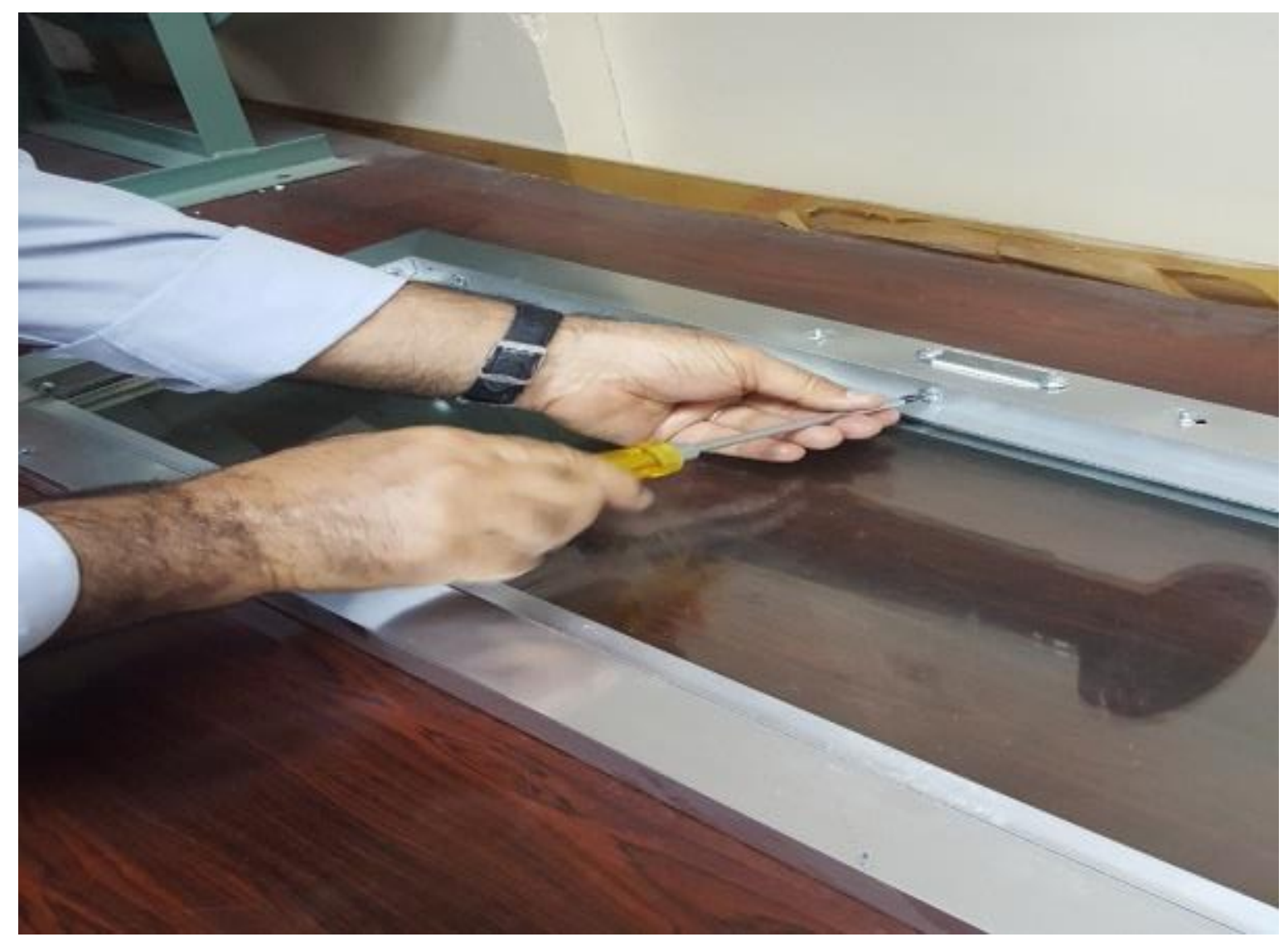

Figure 3. Disassembling one side of the box. 


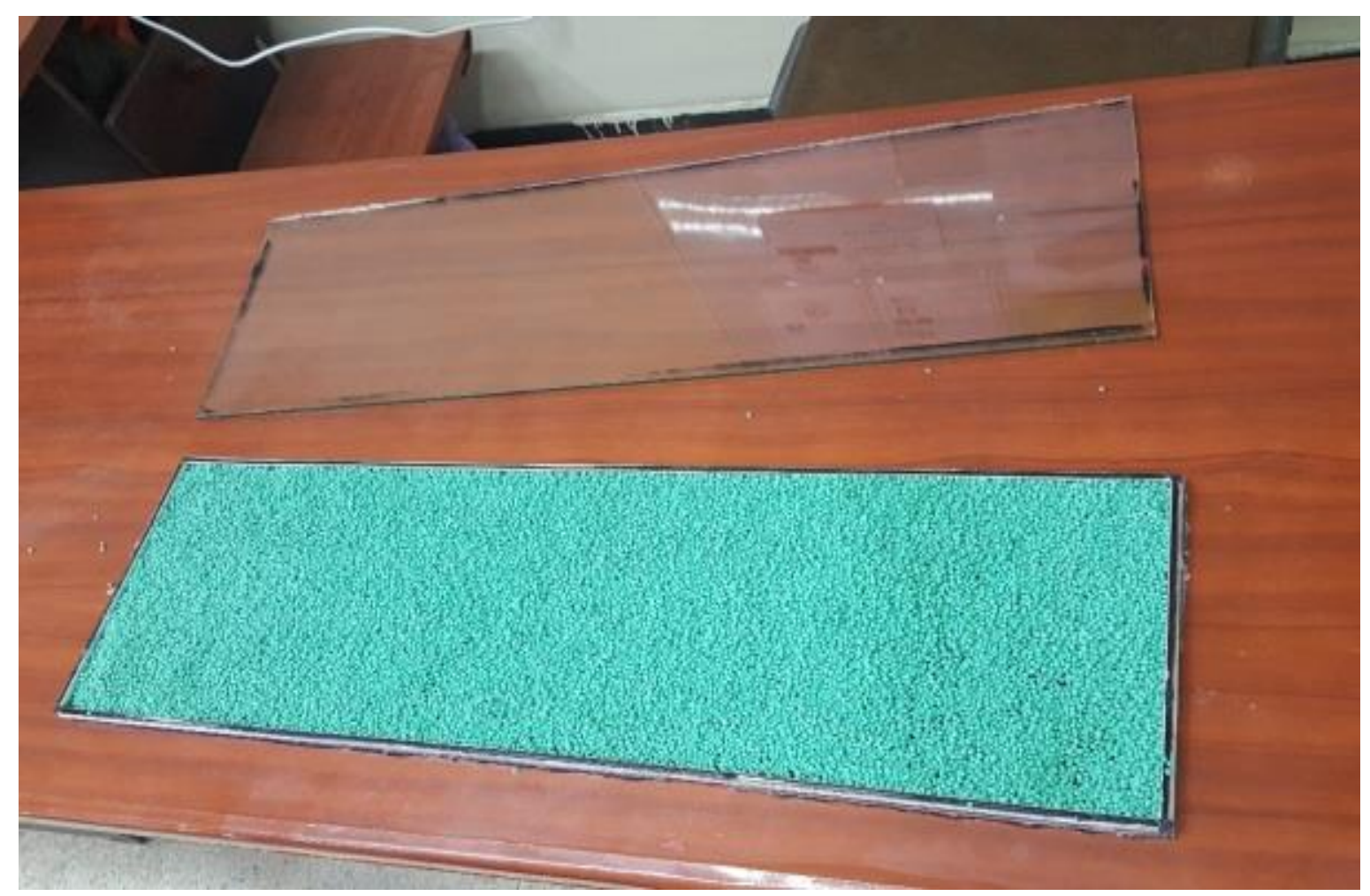

Figure 4. Raising one glass sheet and adding plastic grains to the other sheet.

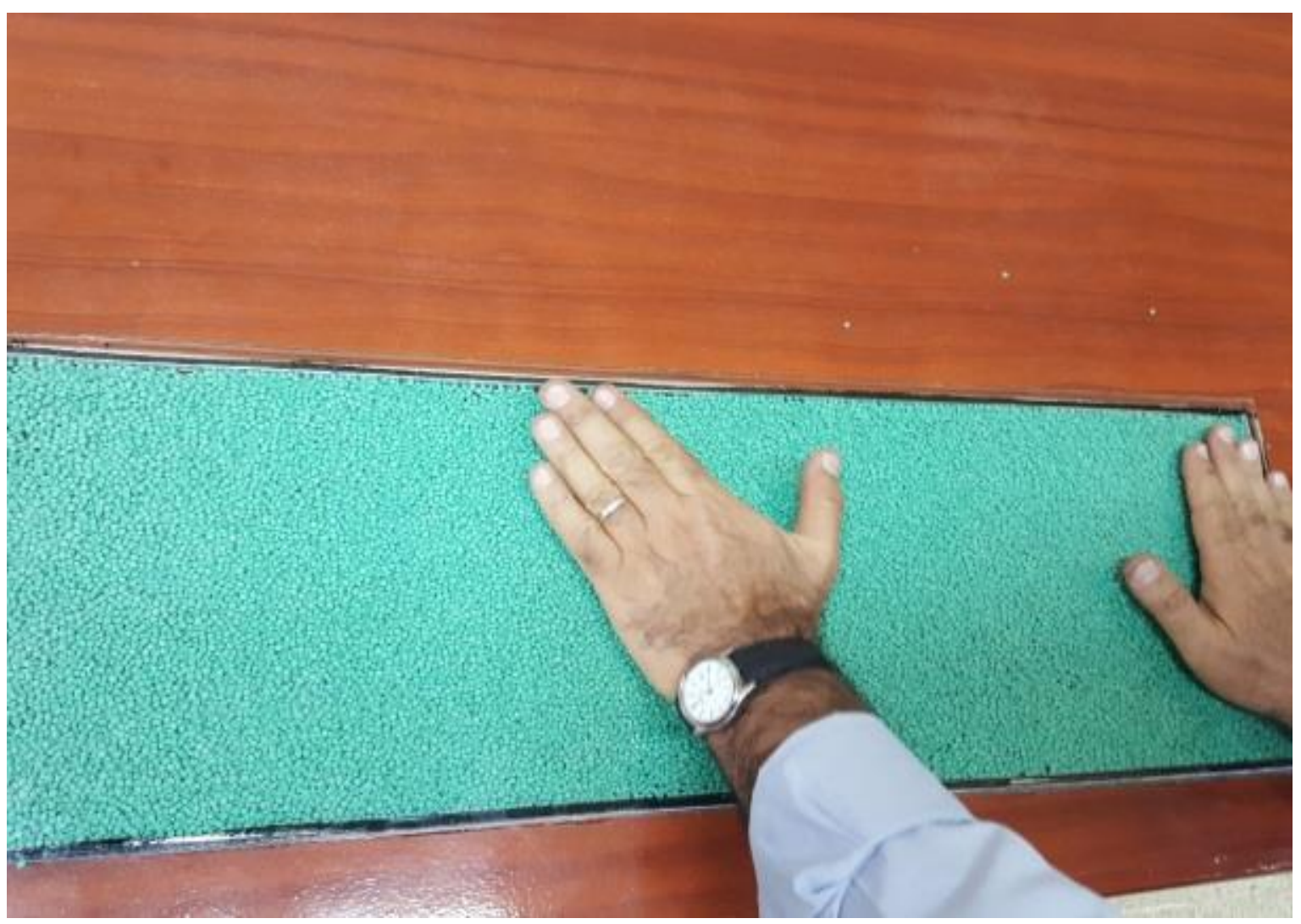

Figure 5. Mounting the raised sheet of glass on the separator. 


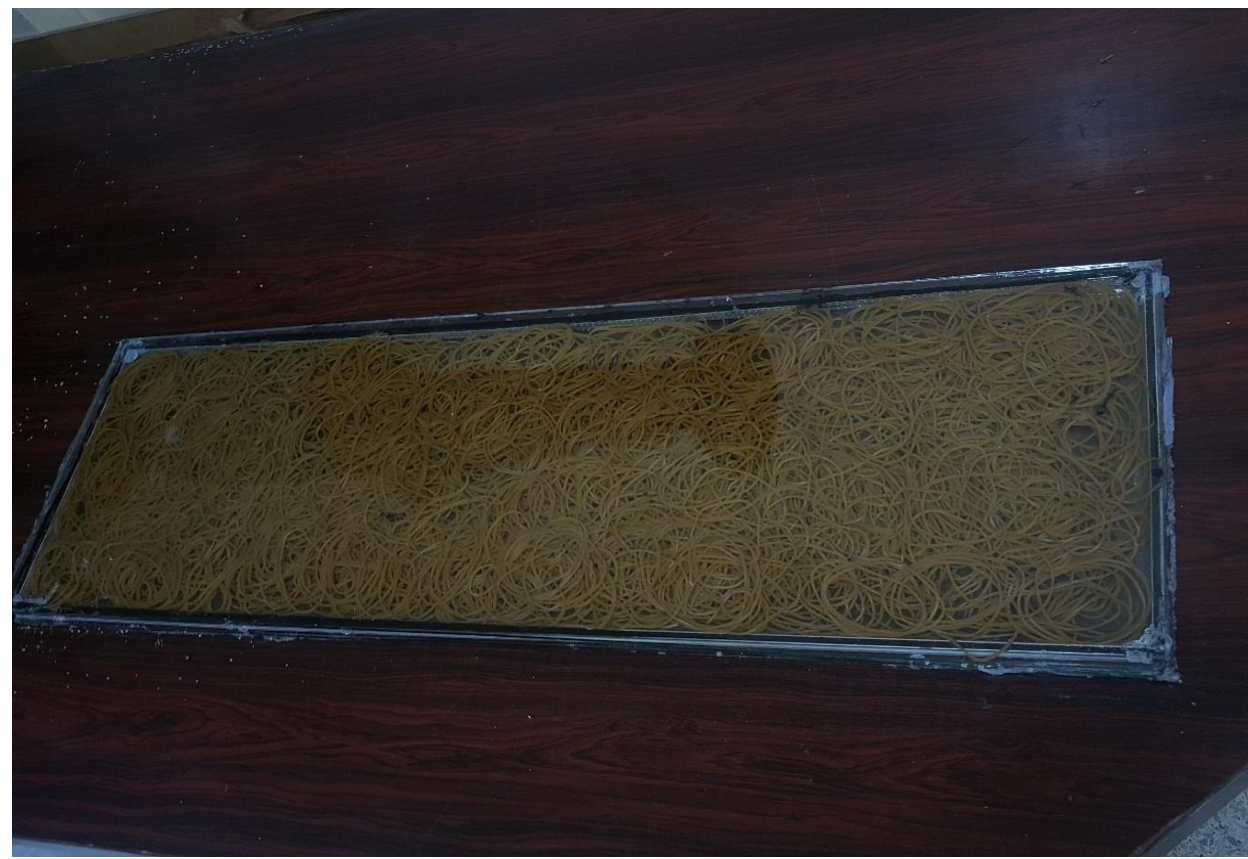

Figure 6. Silicon paste fixing between the sheets and separator.

\subsection{Instruments of Measurement}

\section{(1) Temperature Measurements}

The use of acoustical enclosure to isolate sound sources requires an appropriate study of temperature increase due to the heat transfer from different parts of test machine.

A temperature measurement device is Lutron 4 in 1 (anemometer, humidity, light meter and thermometer). An environmental tester is used to measure the temperature. It is a heavy-duty DC 9V, 6.2 mA battery power supply with a temperature measure scale from $0-100{ }^{\circ} \mathrm{C}$. It connects to a temperature probe of $\mathrm{k}$-type, as shown in Figure (7).

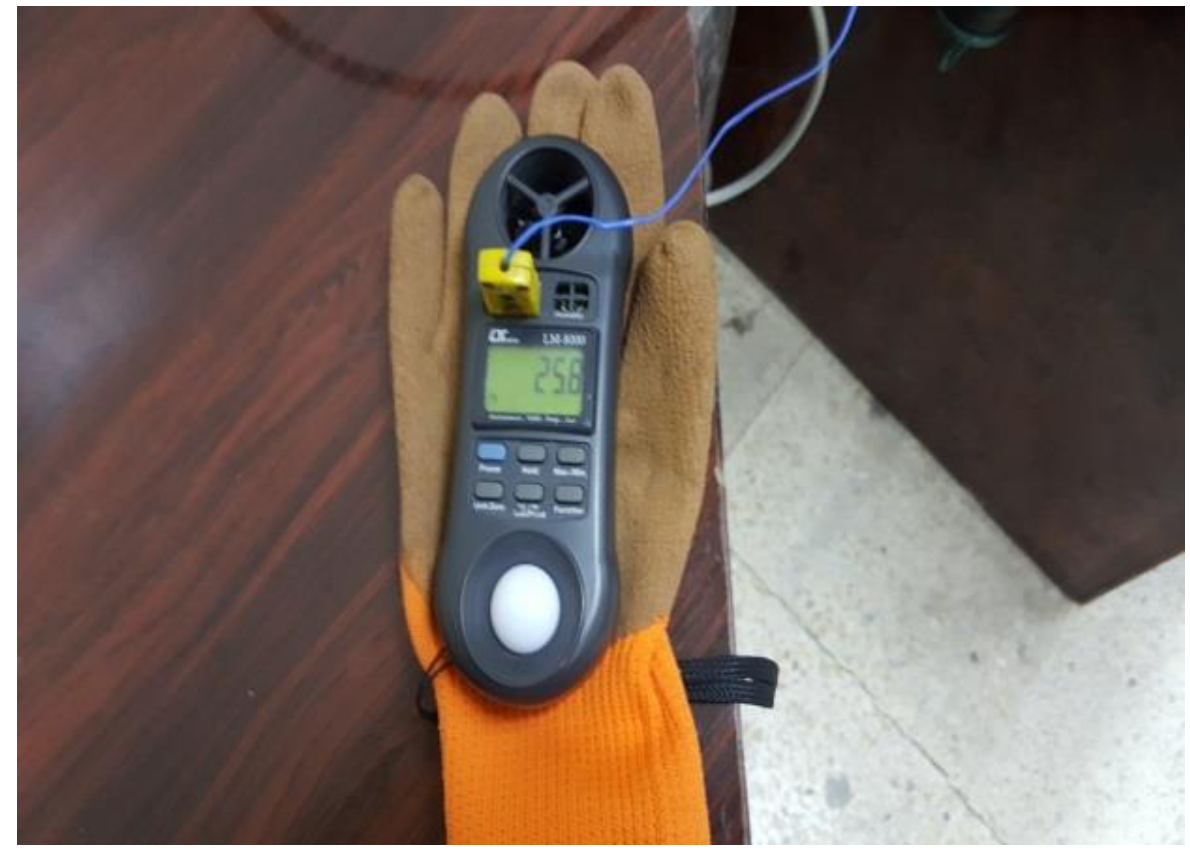

Figure 7. 4 in 1 thermometer device. 


\section{Measurement Procedure}

Measurement is conducted as follows:

(1) A classical calibration of the thermocouple proceeds;

(2) Thermocouple probe sticks on the electrical motor cover (fan revers side) directly above the bearing close $(5 \mathrm{~mm})$ to the shaft by means of a thermal glue, as shown in Figure (8). This point is chosen as the maximum one among measurements employed close to the five bearing positions mentioned before.

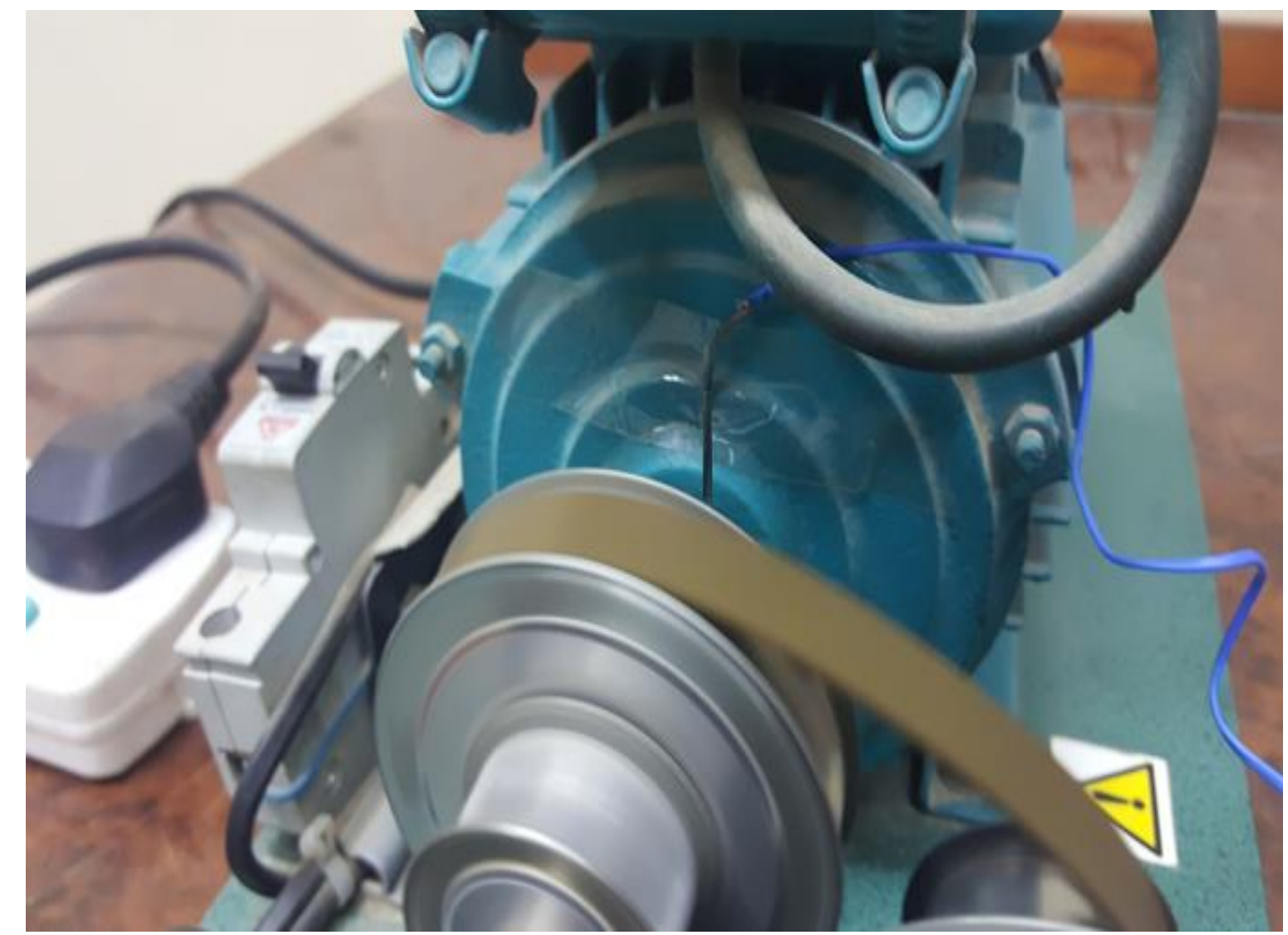

Figure 8. Thermocouple probe position on the motor cover.

(3) Mild steel sample is mounted to the fixture;

(4) The machine is turned on;

(5) Three measures are taken;

- Without the box

- With the box (closed slots)

- With the box (opened slots).

\section{(2) Sound Level Measurements}

Sound level is a particular criteria for noise. It evaluates the efficiency of any sound insulation material. Sound level meter used in the experimentation measurements confirms to the IEC61672-1 Class 2 for sound level meters. It has four dynamic ranges $30-130 \mathrm{~dB}, 31.5-8000 \mathrm{~Hz}$ frequency, (A)/(C) weighting, +1.4 accuracy, 1/2 inch electric condenser microphone and 9 Volt power supply, as shown in Figure (9). 


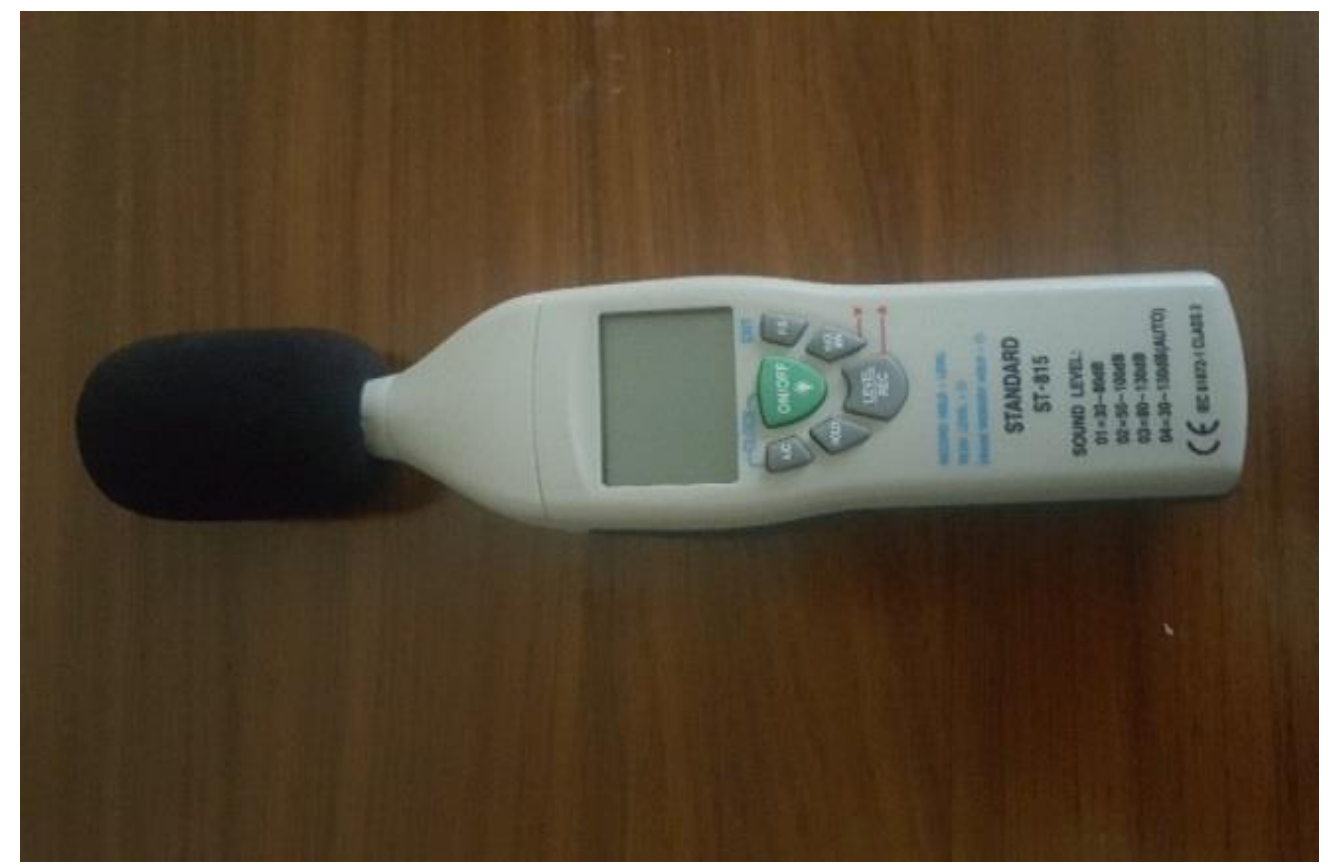

Figure 9. Sound level meter.

\section{Measurement Procedure}

Sound measurements is conducted as follows:

(1) Meter is calibrated

- $\quad$ Selecting A-weighting, fast time, (02)/50-100 dB on meter.

- Inserting microphone into calibrator hole.

- Turning on the calibrator.

- Adjusting CALL potentiometer until $94 \mathrm{~dB}$ is displayed.

(2) Stopping any air wind movement by closing the lab doors, windows, fans and air drawers to avoid other sound sources (fans and drawers) and to fix the air temperature which is directly proportional to sound speed.

(3) Turning off the lights to prevent other sound source.

(4) Turning on the test machine.

(5) Starting measuring the sound level using the meter at three central positions $(0.5,1$ and $1.5 \mathrm{~m})$ from the center line of the machine.

(6) Repeating these measurements in four directions (front, upper, motor side and sample fixture side).

(7) Repeating 5 and 6 paragraphs to include the following cases,

- Without the box,

- With the box (air between glass sheets), as shown in Figure (10),

- With the box (plastic grains between the glass sheets), as shown in Figure (11).

- With the box (rubber fibers between the glass sheets), as shown in Figure (12).

- With the box (sawdust fibers between the glass sheets), as shown in Figure (13).

In order to include a wider range of sound level all of the above measurements are taken by selecting (A) $\&(\mathrm{C})$ weighting each time; the (A) one is for low and human limits of sound, while the (C) one is for higher and machine limits. 


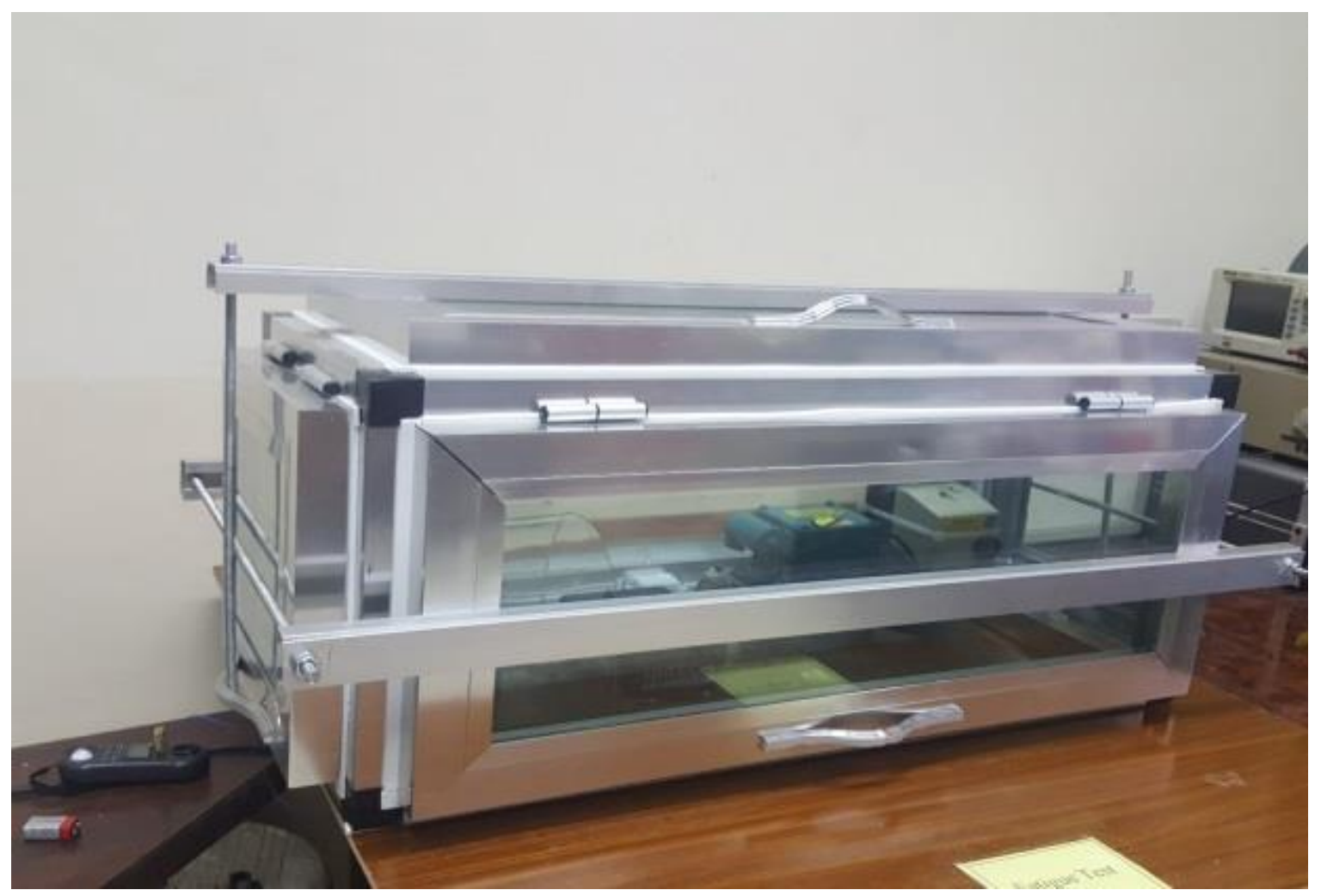

Figure 10. Air filled the gap between the glass sheets.

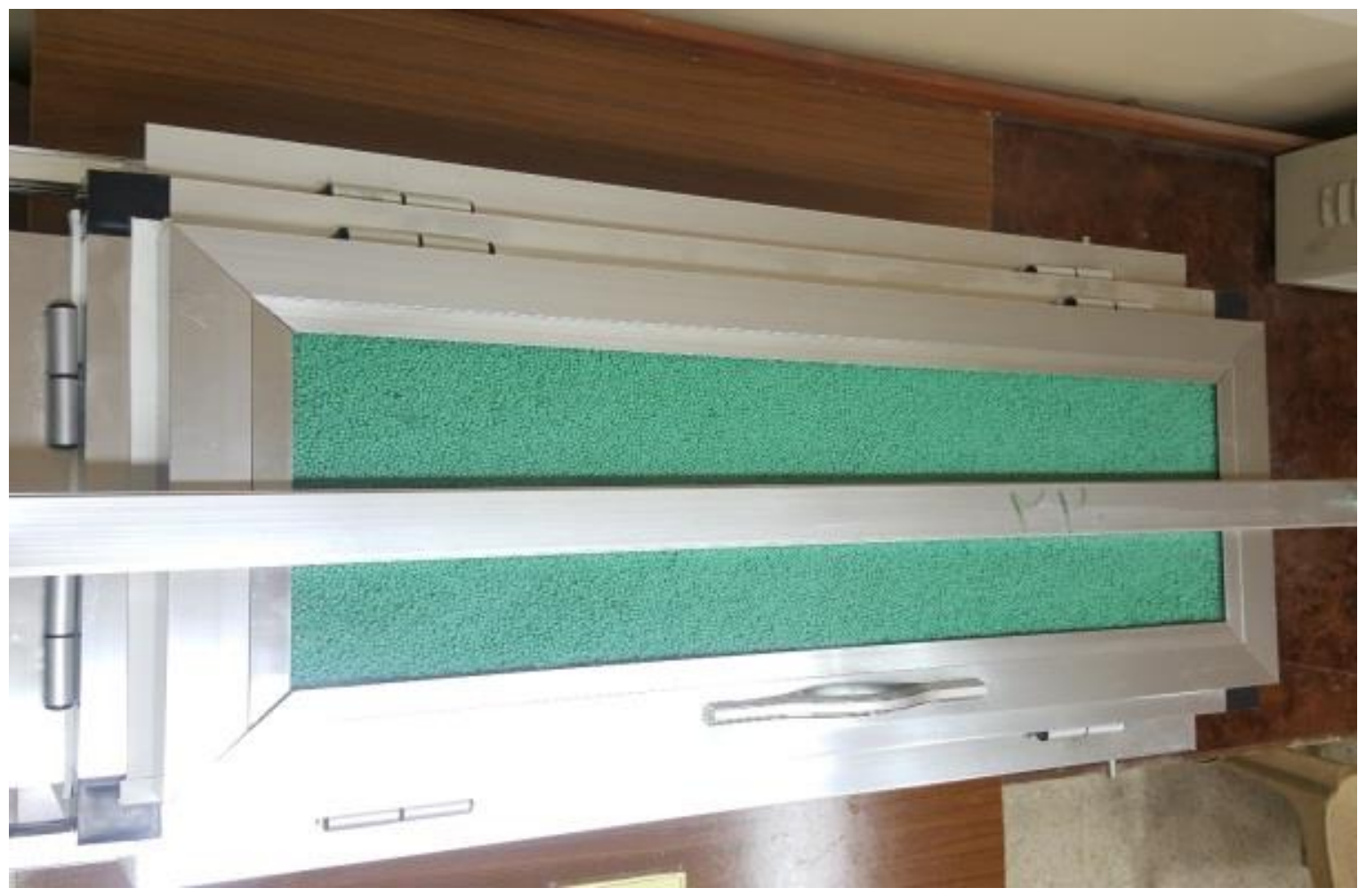

Figure 11. Plastic grains filled the gap between the glass sheets. 


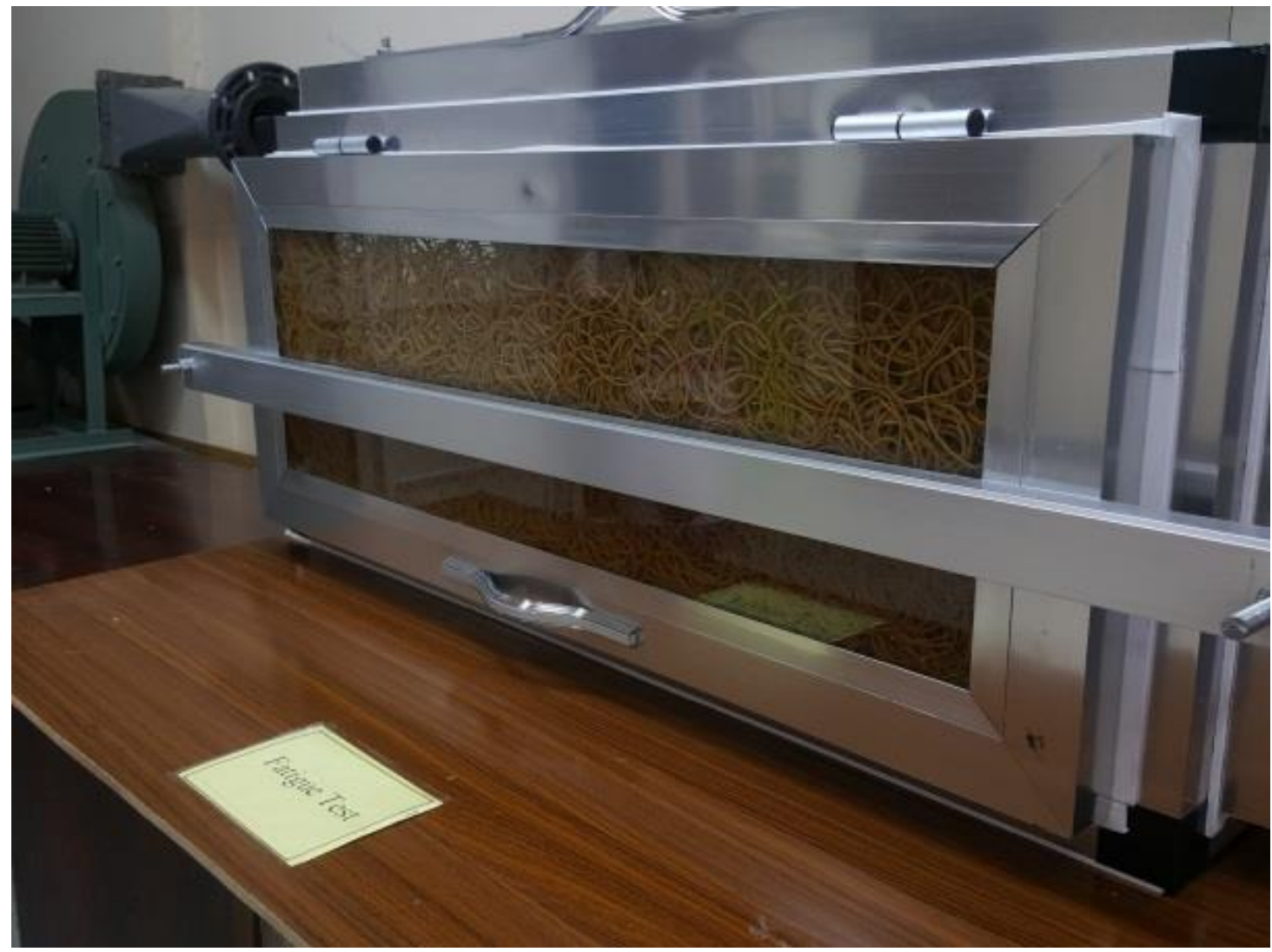

Figure 12. Shredded rubber fibers filled the gap between the glass sheets.

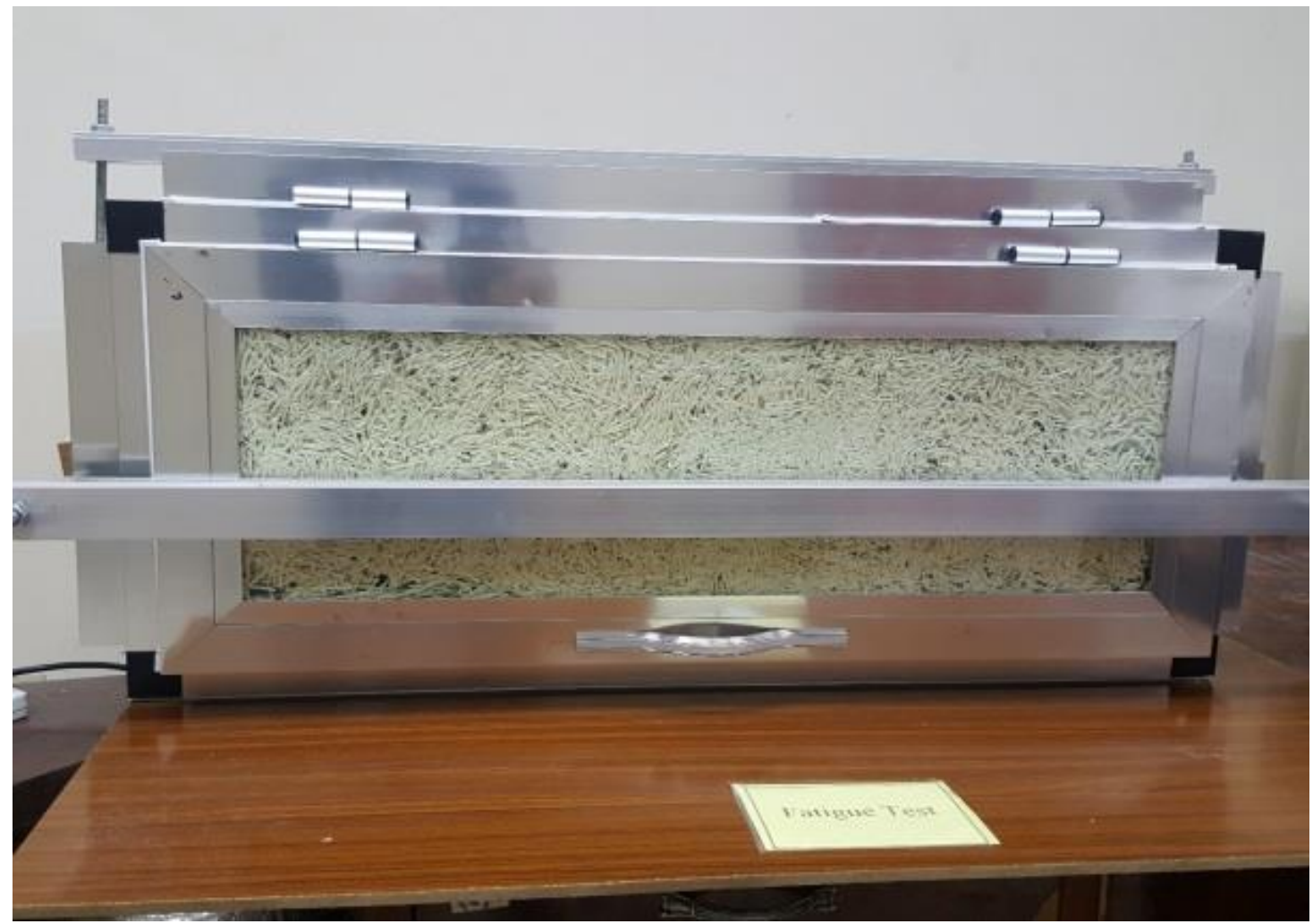

Figure 13. Sawdust fibers filled the gap between the glass sheets. 


\section{Theoretical Analysis}

Since the sound waves propagate inside the lab building, the attenuation of sound comes from the sound source (fatigue test machine) depending mainly on the source itself, the receivers locations and sound absorption inside the lab space. The sound level can be calculated according to the semi-reverberant formula, Vigran [12],

$$
\mathrm{L}_{\mathrm{r}}=\mathrm{L}_{\mathrm{s}}+10 \log \left(\frac{\mathrm{Q}}{\mathrm{A}}+\frac{4}{\sum \mathrm{S} . \alpha}\right)
$$

Where $L_{r}, L_{s}, Q, A, S$ and $\alpha$ represent received sound level in $d B$, sound level ta source in $d B$, directivity index, sound propagation area in $\mathrm{m}^{2}$, space single surface in $\mathrm{m}^{2}$ and sound absorption coefficient, respectively. The directivity index is calculated using the following formula,

$$
\mathrm{Q}=10 \log \frac{\mathrm{I}_{\mathrm{i}}}{\frac{\sum \mathrm{I}}{\mathrm{n}}}
$$

Where, $\mathrm{I}_{\mathrm{i}},\left(\sum \mathrm{I}\right) / \mathrm{n}$ and $\mathrm{n}$, are sound intensity at $\mathrm{i}$-direction in Watts per square meter, average sound intensities in all directions in space at same distance from source and number of intensities, respectively. Table (1) shows the calculated values of $\mathrm{Q}$,

Table 1. $Q$ values.

\begin{tabular}{lcc}
\hline \multirow{2}{*}{ Position } & \multicolumn{2}{c}{ Sound Level $(\mathrm{dB})$} \\
\cline { 2 - 3 } \multicolumn{1}{c}{ A } & $\mathrm{C}$ \\
\hline Front & +0.0553 & +0.0379 \\
Up & +0.1771 & +0.1406 \\
Motor Side & -0.0532 & -0.1180 \\
Sample Fixture Side & -0.1875 & -0.0645 \\
\hline
\end{tabular}

The absorption coefficient for sound of air and double glazing wall with air, plastic grains, rubber and sawdust fibers in between the glass sheets is measured using B \& K 4200 standing wave apparatus employing the small tube of low frequency to measure the different structure wall materials, as shown in Table (2).

Table 2. $\alpha$ values.

\begin{tabular}{lc}
\hline Material & $\alpha$ \\
\hline Air & 0.09 \\
Double-glazed Air Filled & 0.169 \\
Double-glazed Plastic Grains Filled & 0.175 \\
Double-glazed Rubber Fibers Filled & 0.625 \\
Double-glazed Sawdust Fibers Filled & 0.848 \\
\hline
\end{tabular}




\section{Results and Discussions}

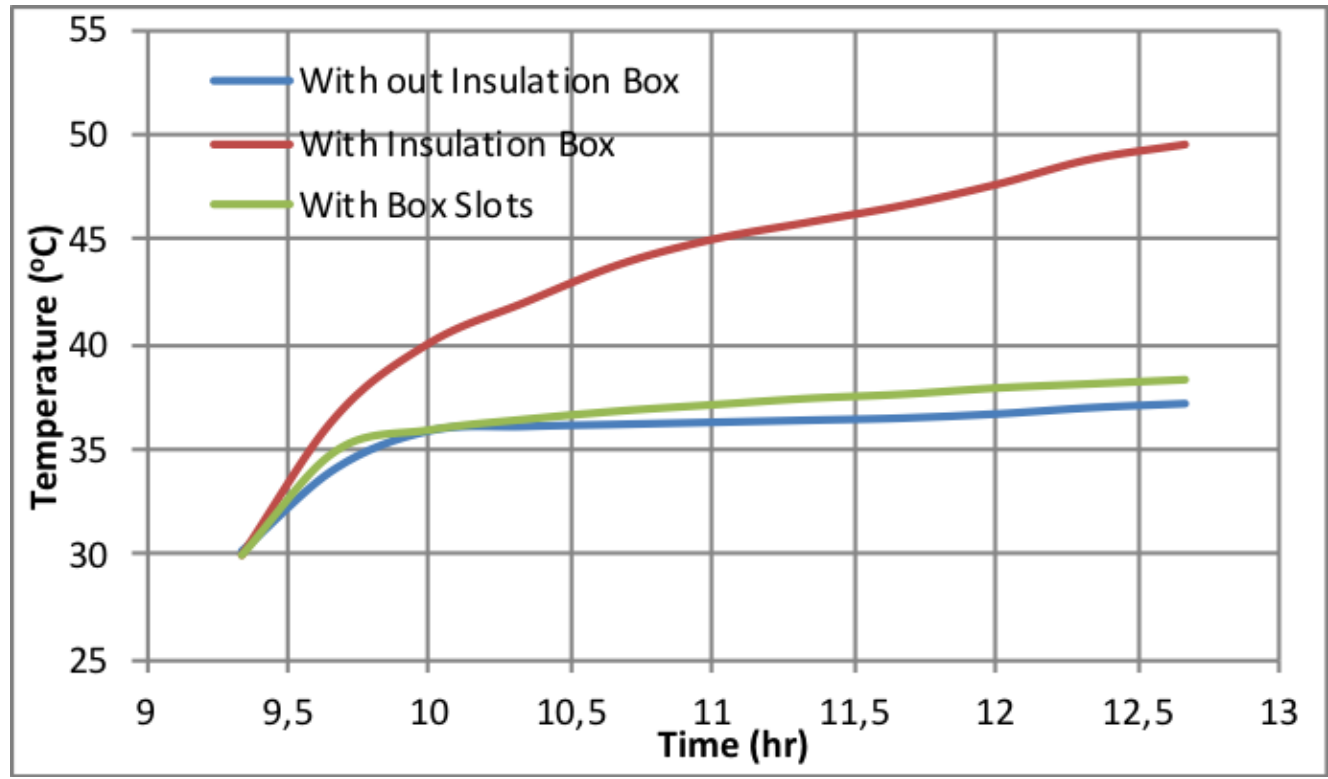

Figure 14. Temperature increase for the highest temperature point of fatigue machine test.

According to quality and quantity records of the measured results, they can be classified into,

\subsection{Fatigue Machine Test Temperature Results}

Figure (14) shows the temperature increase due to friction of the mechanical parts inside the machine test of the five points close to bearings. The bearing of coupling side (reversal to motor fan side) has the highest temperature point after testing it experimentally. An increased amount reaches $23 \%$ at maximum point of difference when putting the insulation box with closed ventilation slots in comparison to bared results (without the box). Figure (14) shows a small increase in temperature between the open slots box and without the box results. The increase in temperature inside the box comes from a natural and forced (fan) convection (mixed). The slot's location makes a draft of the outside air and good ventilation will produce.

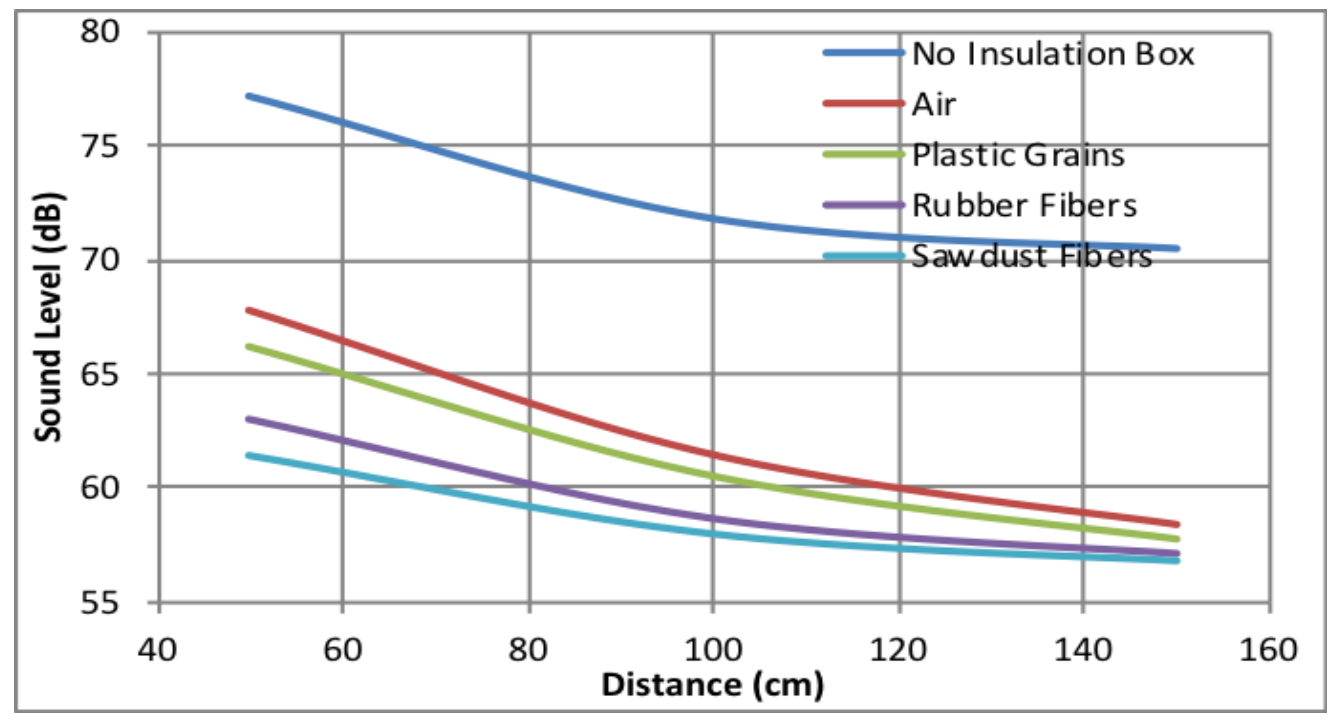

Figure 15. Sound level attenuation with distance at (A) weight measurement from the front side of the test machine. 


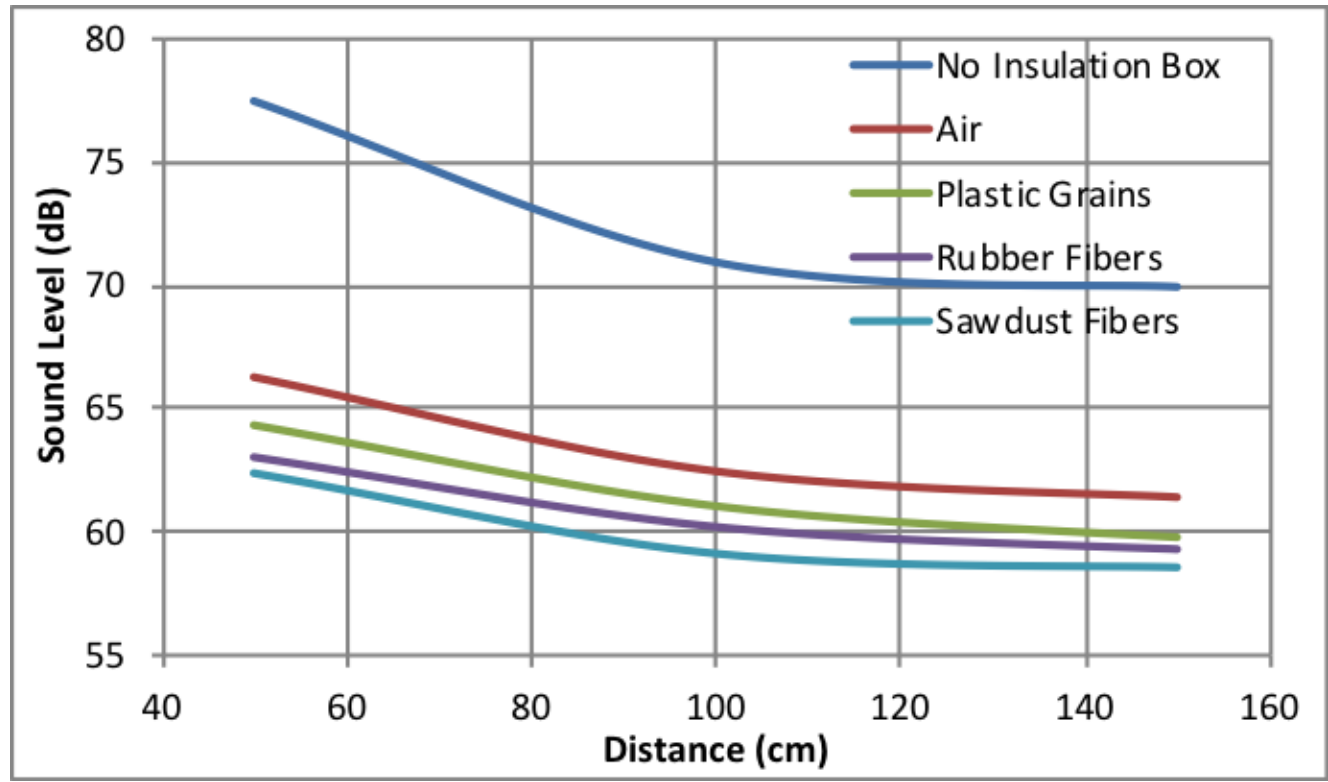

Figure 16. Sound level attenuation with distance at $(C)$ weight measurement from the front side of the test machine.

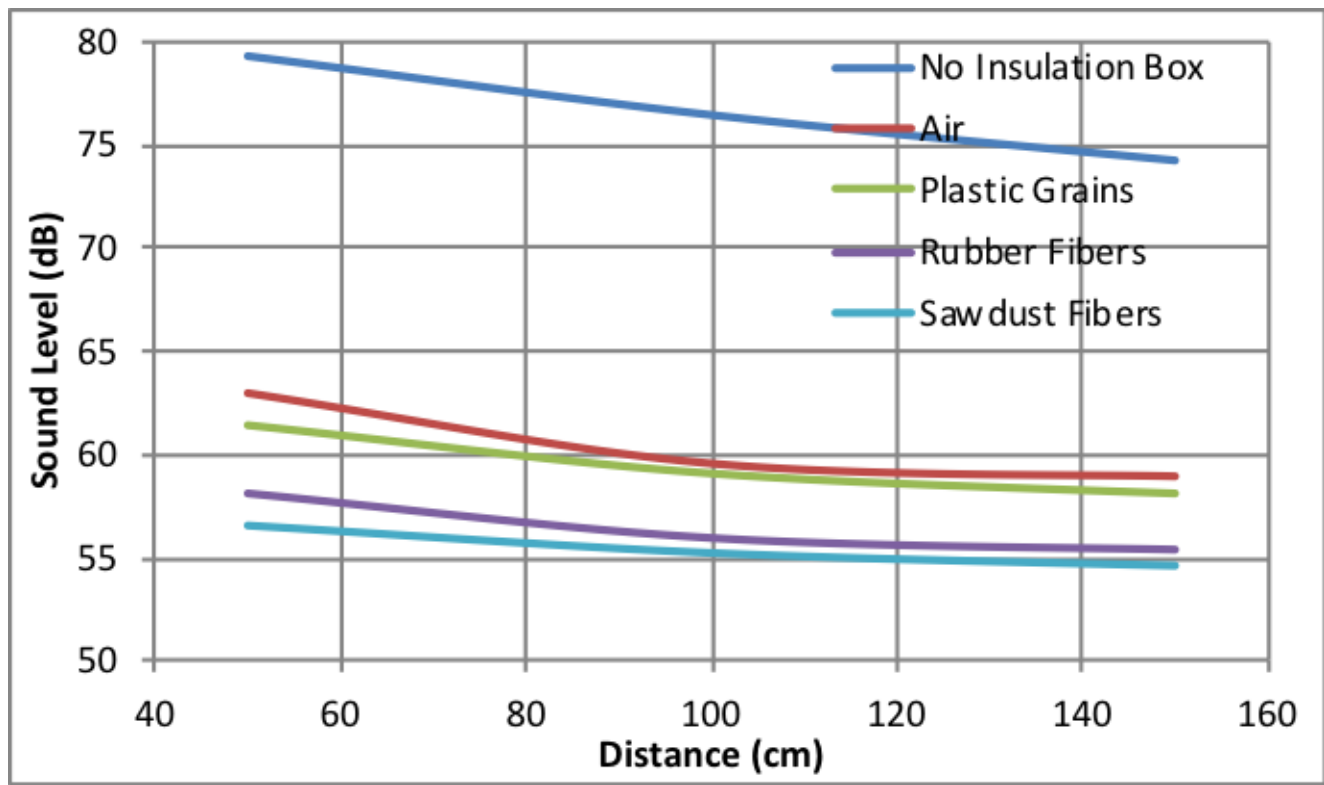

Figure 17. Sound level attenuation with distance at $(A)$ weight measurement from the upward side of the test machine. 


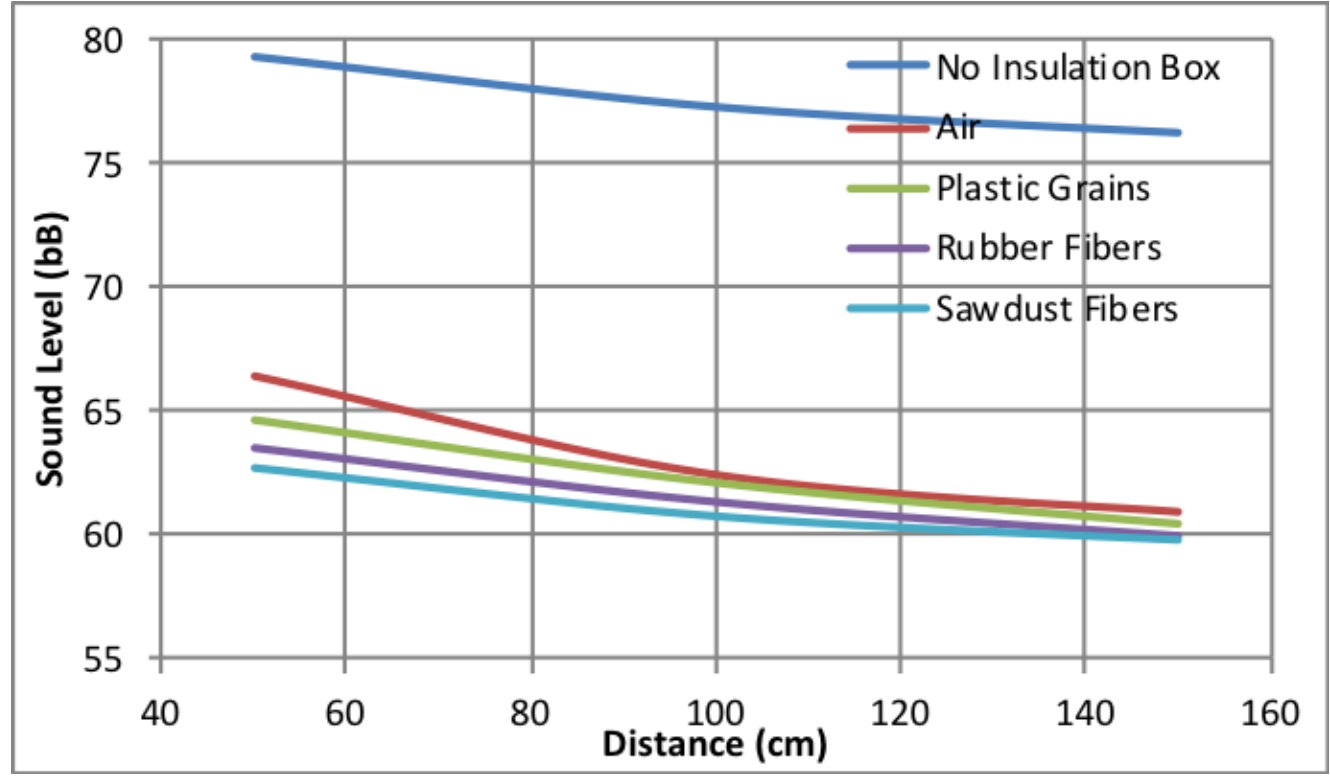

Figure 18. Sound level attenuation with distance at $(C)$ weight measurement from the upward side of the test machine.

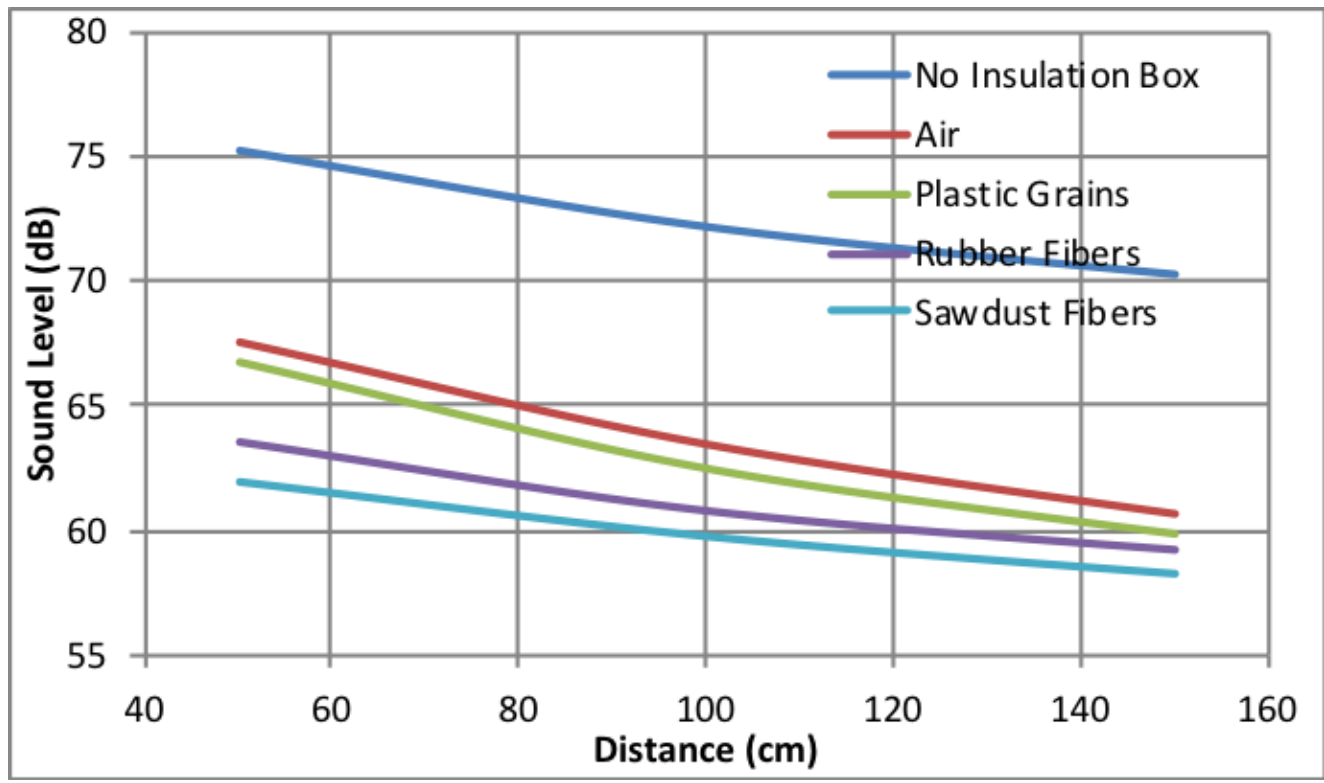

Figure 19. Sound level attenuation with distance at $(A)$ weight measurement from the motor side of the test machine. 


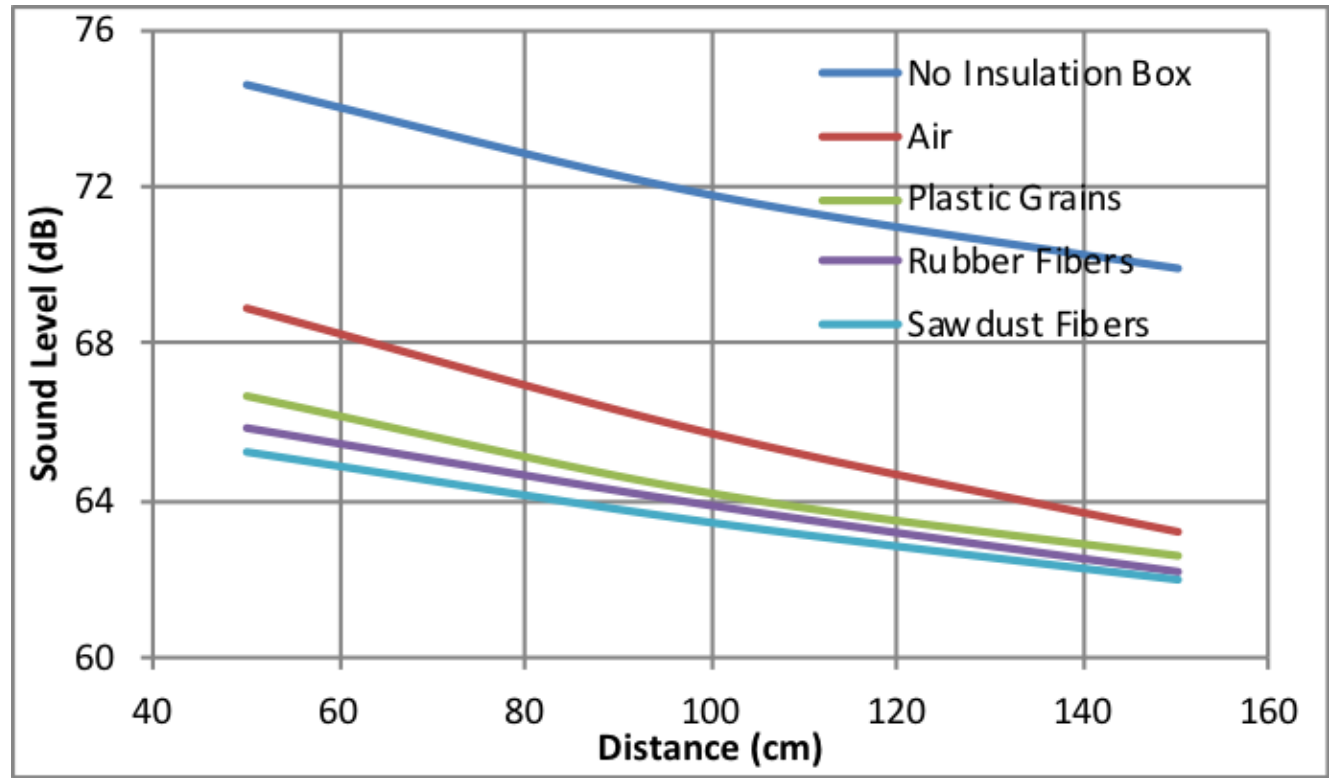

Figure 20. Sound level attenuation with distance at $(C)$ weight measurement from the motor side of the test machine.

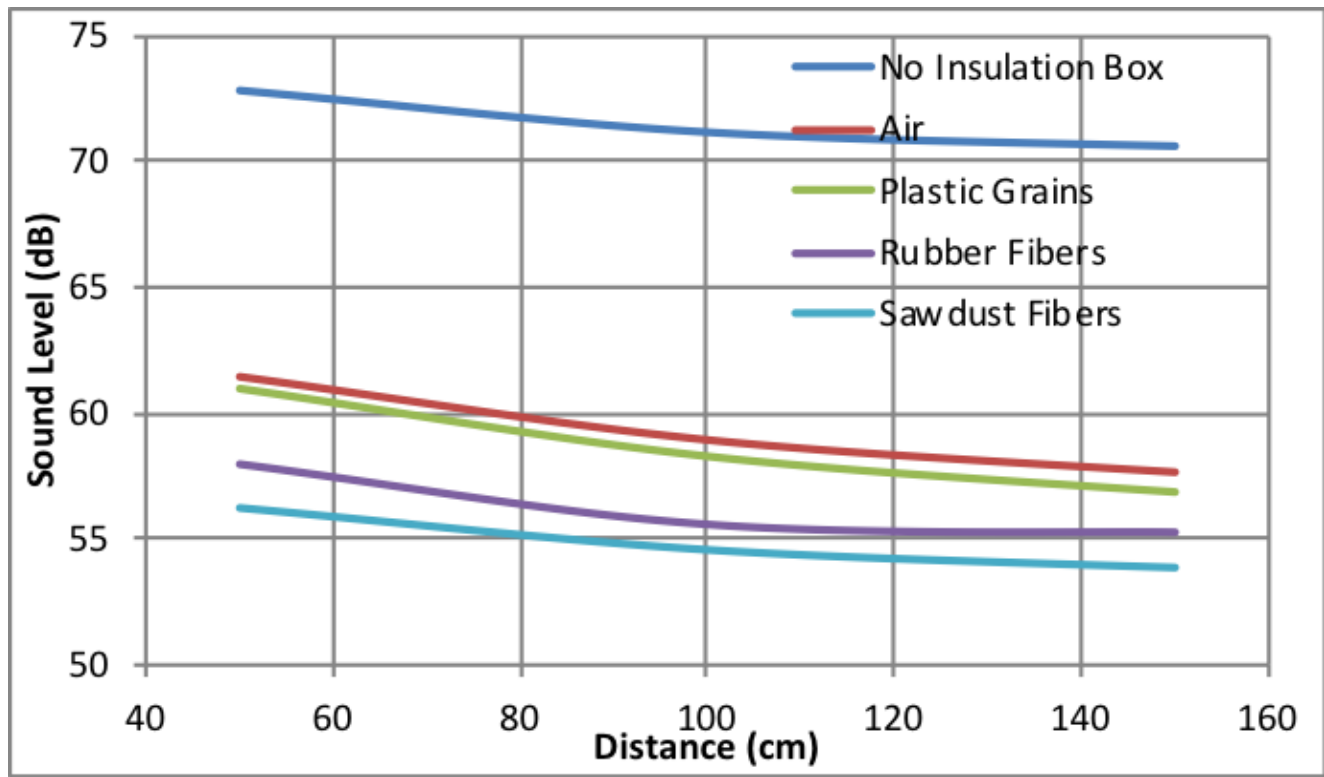

Figure 21. Sound level attenuation with distance at (A) weight measurement from the sample fixture side of the test machine. 


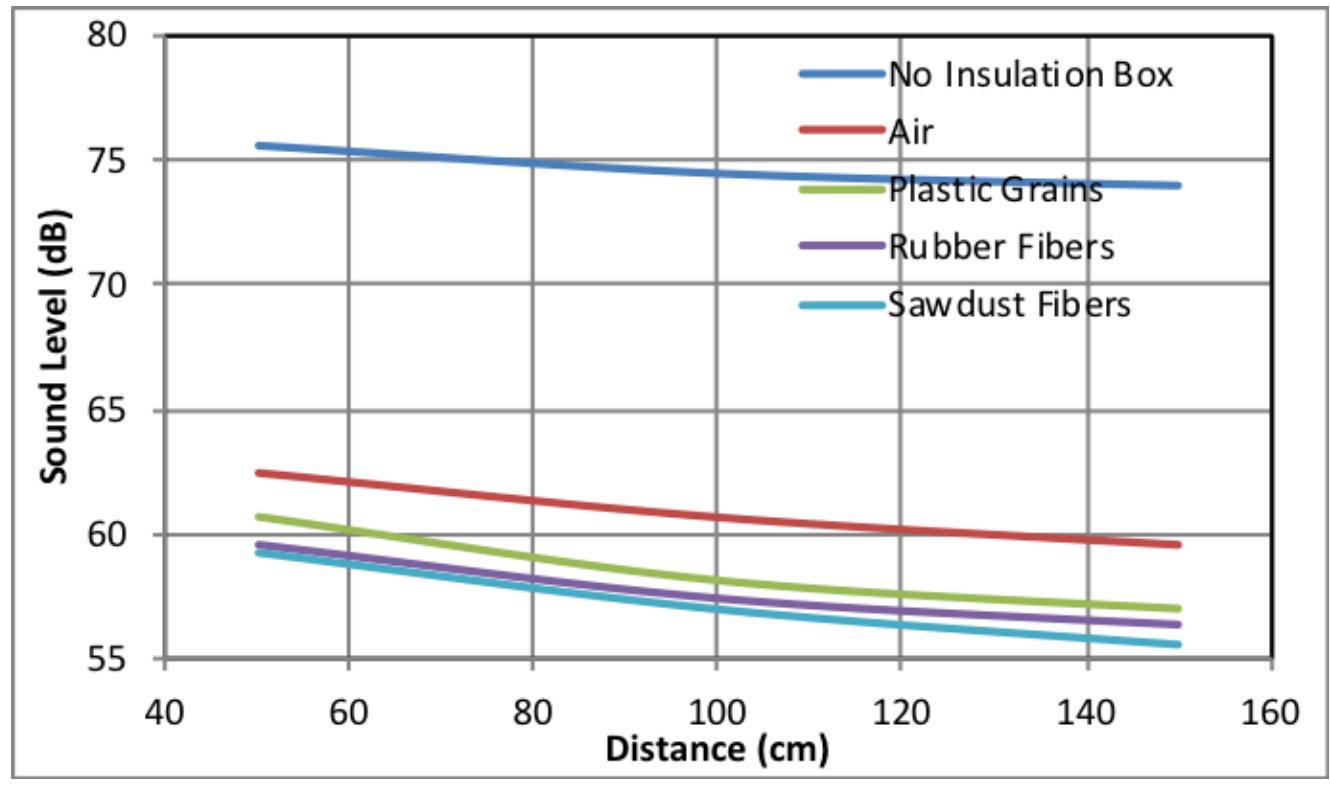

Figure 22. Sound level attenuation with distance at $(C)$ weight measurement from the sample fixture side of the test machine.

\subsection{Sound Level Measurement Results}

Figure (15-22) show the sound level results for cases of the machine without putting the insulation box and the insulation box with air, plastic grains, rubber fibers or sawdust fibers between the box glass sheets, using the (A) and (C) measure weights separately to include the widest range of sound level. The results show that higher attenuation takes place with the sawdust fiber than with the rubber fiber followed by plastic grain materials and air gradually. These results are taken for front, upward, motor and sample fixture sides for convincement and to show the real difference in attenuation amount in direction, distance and type of sound insulation material in addition to examining two types of measuring weights.

The main causes of making such attenuation changes at fixed direction and fixed distance are due to:

- Material nature;

- Amount of grain and fiber per unit area (attenuation increases as grain or fiber size decreases);

- More complex shape of grain or fiber will increase the surface area that surrounded by air (sawdust fiber has higher complex surface area then rubber fiber and then plastic grain);

- Different measuring weights of the meter.

The main causes of attenuation differences at fixed direction for the same insulation material are due to:

- $\quad$ Sound attenuation is directly proportional with increase in distance;

- Effect of sound reflection from facing the wall or roof;

- $\quad$ Difference in measuring the sound level weighting.

The main causes of attenuation differences at fixed distance for the same insulation material are due to:

- Type of sound source point for the motor and sample fixture sides or line for the upper and front side directions.

- $\quad$ Differences between the bearing load effect on the different parts of the machine.

- $\quad$ Different reflections that depend on various distances from direct facing of the walls or roof.

- Ventilation slot existence (they are on the motor and sample sides only).

\subsection{Effect of Ventilation Slots}

Sound level results for front and upper directions show no change between the opened and closed slots of the insulation box for all types of insulation materials. This is certain since the slots are not on their sides.

While the sound level results for motor and sample fixture directions of the open slotting show about 5\% decrease at maximum in sound attenuation than the closed slot results for all types of examined materials. 
This is since the inlet slot is at the motor side and the exit slot at the sample fixture side. Actually, this lower percent is impalpable on the outline of the attenuation process.

It is worth mentioning that all results discussed in Figure (15-22) are with the open slots.

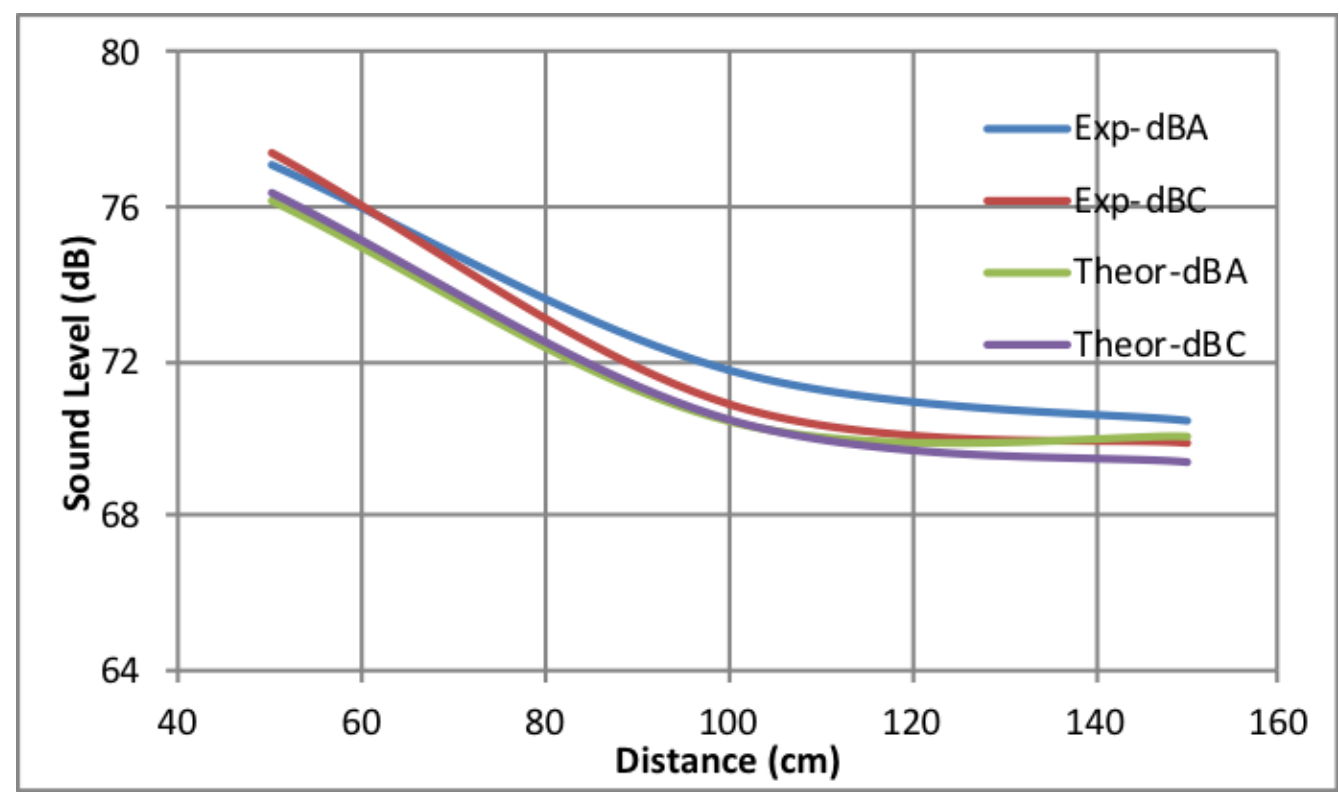

Figure 23. Comparison between experimental and theoretical attenuation with distance from the front side for no insulation.

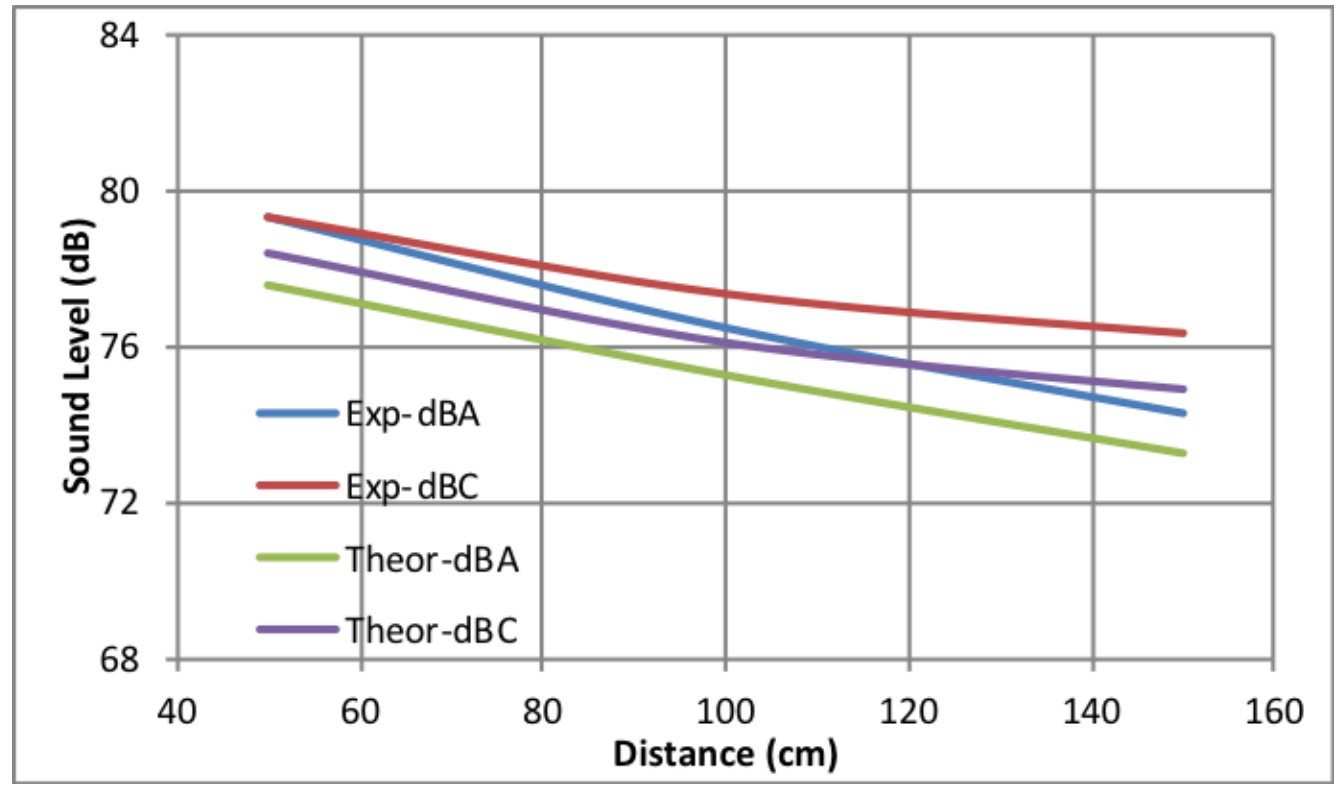

Figure 24. Comparison between experimental and theoretical attenuation with distance from the upward side for no insulation. 


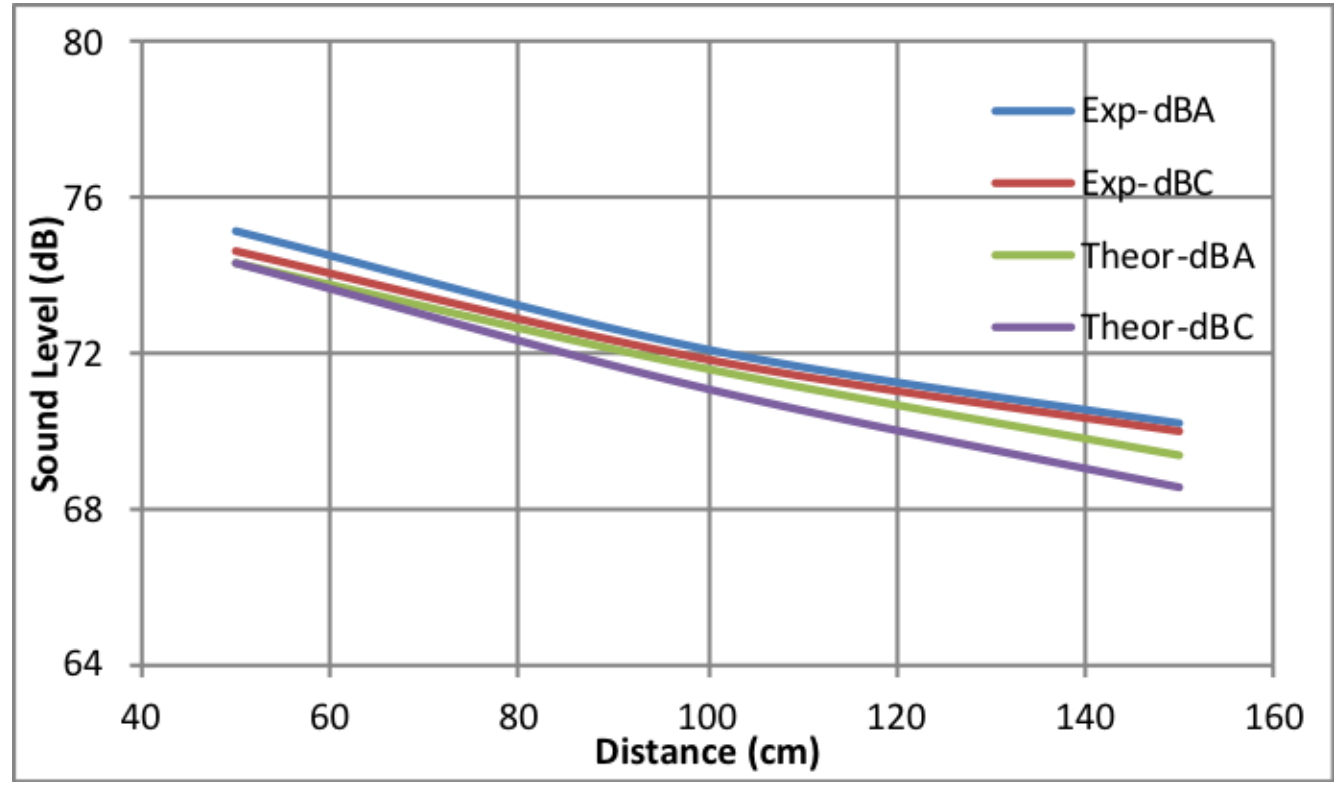

Figure 25. Comparison between experimental and theoretical attenuation with distance from the motor side for no insulation.

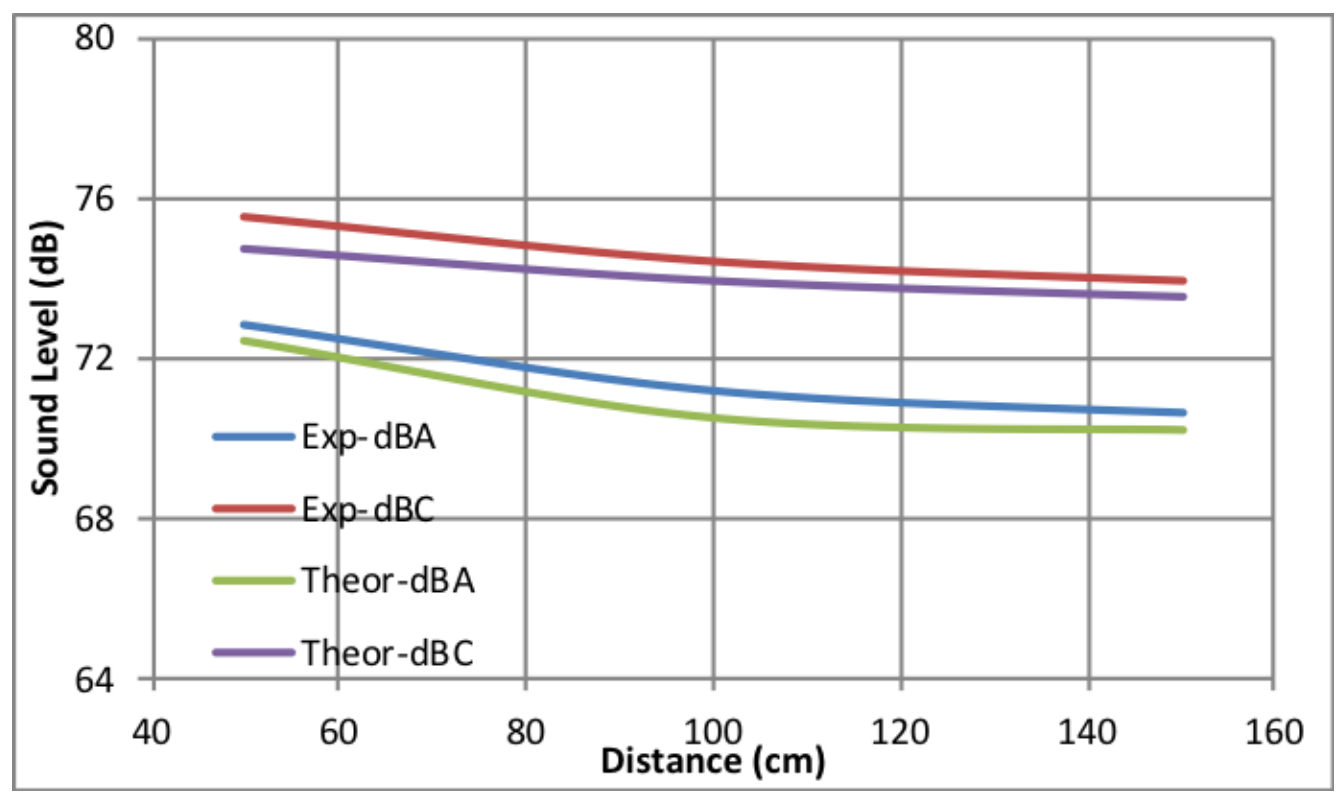

Figure 26. Comparison between the experimental and theoretical attenuation with distance from the sample fixture side for no insulation. 


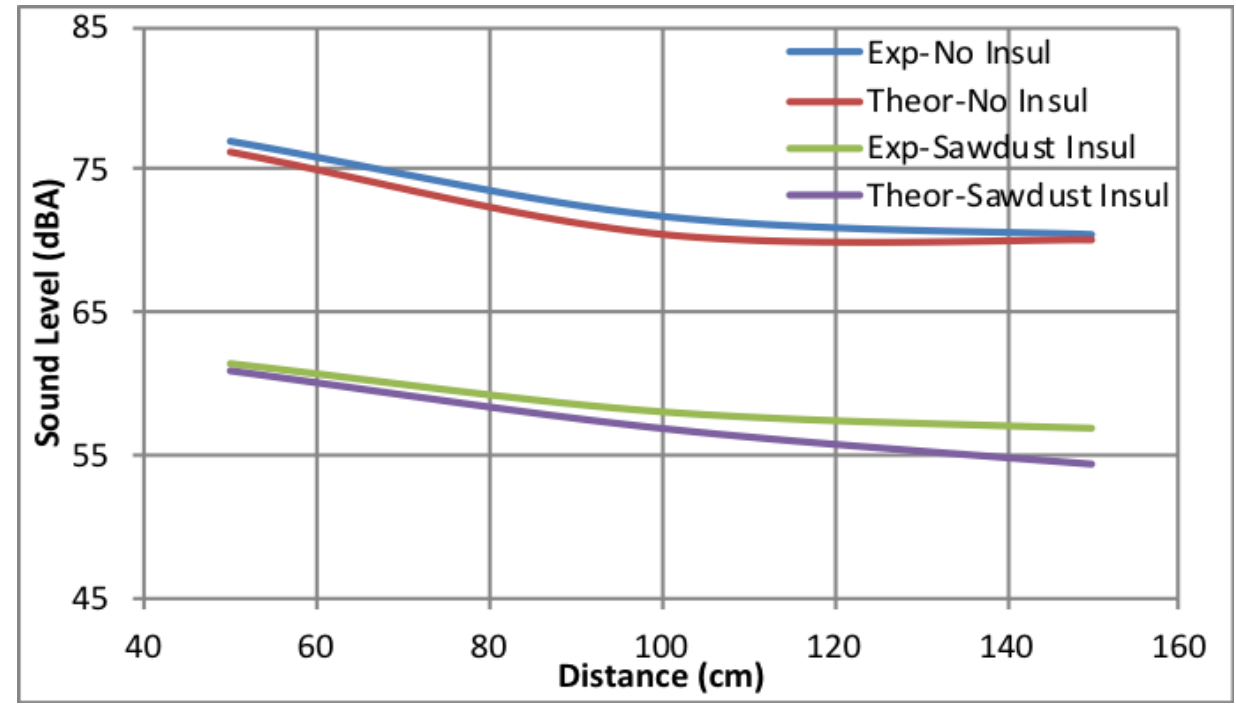

Figure 27. Comparison between the experimental and theoretical attenuation with distance from the front side for no insulation and sawdust insulation box at (A) meter weight.

\subsection{Comparison with Theoretical Results}

(1) Figure (23-26) show the comparison between measured (A) and (C) meter weighting experimental and theoretical results calculated according to equations (1) and (2), which were discussed previously in the theoretical analysis for the non-insulation box in order to validate the experimental results. Good agreement is attend, since the error estimated has not reached $2 \%$ at maximum for the same weight of measure on the four directions. Nevertheless this error is coming from accuracy of $\alpha$ measurement.

(2) Figure (27) shows the comparison between the experimental and theoretical attenuation from the front side for no insulation and the sawdust insulation box at (A) meter weight. These results show that about $25 \%$ amount of the sound attenuation took place. Again, the figure shows the good agreement between the experimental and theoretical results.

\section{Conclusions}

The measures, calculations and results from the present study can be concluded as follows:

(1) Average attenuation by using double glazed aluminum framed box with air in between the glass sheets of the box walls reaches about $18 \%$.

(2) Average attenuation with plastic waste grains that replaces air in between the glass sheets reaches about $20 \%$.

(3) Average attenuation with rubber waste fibers replaces air in between the glass sheets reaches about $22 \%$.

(4) Average attenuation with sawdust waste fibers replaces air in between the glass sheets reaches about $25 \%$.

(5) Aluminum frame, $(6 \mathrm{~mm})$ thickness glass, double glazing, air or waste types all contribute to the attenuation process.

(6) Using aluminum due to cheap, lightweight and good metal sound attenuated.

(7) Multi-layer glass at higher thickness increases the sound attenuation process.

(8) Using of plastic and rubber synthetic waste fibers helps the environment cleanliness from disposable bottles and tire wastes.

(9) Using sawdust biological waste origin also assists the sustainability of our environment.

(10) All attenuation of the sound level contributes to the noise (internal or external) removal of the sound sources like that produced from different types of machines.

(11) Specifically sound level attenuation creates good and higher comfort study and lab environment.

(12) Insulation box ventilation is required and there is a relation between the slots size and box size, as well as the machine generated amount of heat in order to keep a maximum decrease of sound. 


\section{Acknowledgment}

Great thanks first goes to Allah. Thanks to the current and previous head of the Mechanical Engineering Department and to all assistance from the colleagues and research assistants.

\section{References}

[1] Australian Government publishing Service: National Code of Practice for Noise Management and Protection of Hearing at Work, $3^{\text {rd }}$ Edition, Canberra, NOHSC: 2009.

[2] Suter A. H.: Administrative Conference of the United States, Noise and its Effects, 1991.

[3] Berglund B., Lindvall T., (Eds): Community Noise, Archives of the Center for Sensory Research, 1995; 2: 1-195, This Document is An Updated.

[4] M Caniato, F. Betarello, C. Schmid, P Fausti: Assessment Criterion for Indoor Noise Disturbance in the Presence of Low Frequency Sources, Applied Acoustics 113 (2016) 22-33.

[5] Schultz, T.: Syntheses of Social Surveys on Noise Annoyance, J. of Acoust. Soc. Am., 1978, PP 62, 377-405.

[6] Jakobsen J. Danish: Guidelines on Environmental Low Frequency Noise, Infrasound and Vibration, J Low Frequency Noise, Vib ACT Control (2001); 20(3): 141-8.

[7] Drexl M., Otto L., Wiegrebe L., Marquardt T., Gürkov R., Krause E.: Sound Exposure Causes Reversible Long-Term Changes of Cochlear Transfer Characteristics, Hear Res (2016); 332(01): 879.

[8] WHO, World Health Organization: Guidelines for Community Noise, Geneva, Switzerland, 1999.

[9] Smith B.J., Peters R.J. and Owen S.: Acoustic and Noise Control, England, Addison, Longman Limited, 1996.

[10] Templeton D.: Acoustics in the Built Environment, Architecture Press, British, 1997.

[11] Environmental Protection Department, Highways Department: Guidelines on Design of Noise Barriers, Government of the Hong Kong SAR, Second Issue, Jan. 2003.

[12] Vigran, T.E.: Building Acoustics, Taylor \& Francis, USA and Canada, 2008.

[13] Departments of the Army and Air Force, TM5-8054/ AFJMAN 32-1090: United Facilities Criteria (UFC) Noise and Vibration Control, Washington, DC, 2003.

[14] H. M. Miedema, C. G. Oudshoorn: Annoyance from Transportation Noise: Relationships with Exposure Metrics DNL and DENL and Their Confidence Intervals, Environmental Health Perspectives (2001); 109(4).

[15] Perrson K, Björkman M, Rylander R.: Loudness, Annoyance and dBA in Evaluating Low Frequency Sounds, J Low Freq Noise Vib (1990); 9(1).

[16] Vercammen M. L. S.: Low-Frequency Noise Linits, J Low Freq Noise Vib (1992); 11:7-13.

[17] Vercammen M. L. S.: Setting Linits for Low Frequency Noise, J Low Freq Noise Vib (1989); 8:105-8.

[18] Bradley, J.S.: Noise Control in Buildings: Sound in Rooms, Transport Canada and the Institute for Research in Construction, National Research Council, 1985.

[19] Kuttruff H.: A Simple Iteration Scheme for the Computation of Decay Constants in Enclosures with Diffusely Reflecting Boundaries, The Journal of the Acoustical Society of America 98, 288-293 (1995); https://doi.org/10.1121/1.413727.

[20] Asdrubali, F.: Survey on the acoustical properties of new sustainable materials for noise control, Euronoise, (2006); 30.

[21] Asdrubali, F., Schiavoni, S., and Horoshenkov, K.: A review of sustainable materials for acoustic applications, Building Acoustics (2012); 19(4), 283-312.

[22] Giada Kyaw Oo D'Amore, Marco Caniato, Andrea Travan, Gianluca Turco, Lucia Marsich, Alessio Ferluga, Chiara Schmid: Innovative Thermal and Acoustic Insulation Foam from Recycled Waste Glass Powder, Journal of Cleaner Production 165 (2017), PP.1306-1315.

[23] Arenas, J. P., and Crocker, M. J.: Recent trends in porous sound-absorbing materials, Sound \& Vibration (2010); 44(7), 12-18.

[24] Sukontasukkul P.: Use of crumb rubber to improve thermal and sound properties of pre-cast concrete panel, Construction \& Building Materials, (2009), Vol. 23 No. (2), pages1084-1092.

[25] Ecosurfaces: Ecore Commercial Flooring, (2014), PO Box 4944, Lancaster, PA 17604-4944, USA, http://www.ecosurfaces.com 
[26] Asdrubali F., D'Alessandro F., Schiavoni S.: A review of unconventional sustainable building insulation materials, Sustainable Materials and Technologies 4 (2015) 1-17.

[27] Koizumi, T., Tsujiuchi, N., and Adachi, A. (2002): The development of sound absorbing materials using natural bamboo fibers, High performance structures and composites, 4, 157-166.

[28] Yang, W. D., and Li, Y.: Sound absorption performance of natural fibers and their composites, Science China-Technological Sciences (2012); 55(8), 2278-2283.

[29] Sagartzazu, X., Hervella-Nieto, L., and Pagalday, J. (2008): Review in sound absorbing materials, Archives of Computational Methods in Engineering 15(3), 311-342.

[30] Allard, J. F., and Daigle, G. (1994): Propagation of sound in porous media: Modeling sound absorbing materials, The Journal of the Acoustical Society of America 95(5), 2785-2785.

[31] Voronina, N.: Acoustic properties of fibrous materials, Applied Acoustics (1994); 42(2), 165-174.

[32] Li, Y., Luo, Y., and Han, S. (2010): Multi-scale structures of natural fibers and their applications in making automobile parts, Journal of Biobased Materials and Bioenergy 4(2), 164-171.

[33] Bahrambeygi, H., Sabetzadeh, N., Rabbi, A., Nasouri, K., Shoushtari, A. M., and Babaei, M. R.: Nanofibers (PU and PAN) and nanoparticles (Nanoclay and MWNTs) simultaneous effects on polyurethane foam sound absorption, Journal of Polymer Research (2013); 20(2), 1-10. 